\title{
The State-Level Impact of Uncertainty Shocks
}

\author{
Haroon Mumtaz* \\ Laura Sunder-Plassmann ${ }^{\dagger}$ \\ Angeliki Theophilopoulou ${ }^{\ddagger}$
}

September 4, 2017

\begin{abstract}
This paper uses a FAVAR model with stochastic volatility to estimate the impact of uncertainty shocks on real income growth in US states. The results suggest that there is a large degree of heterogeneity in the magnitude and the persistence of the response to uncertainty shocks across states. The response is largest in Michigan, Indiana and Arizona while the real income in states such as New York, Alaska and New Mexico seems less sensitive to uncertainty. We relate the cross section of responses to state-level characteristics and find that the magnitude of the decline in income is largest in states with a large share of manufacturing and construction industries, a larger share of small firms, a high fiscal deficit, a less rigid labour market and a more volatile housing market. In contrast, a higher share of mining industries and larger inter-governmental fiscal transfers ameliorate the impact of uncertainty.
\end{abstract}

JEL Codes: C15,C32, E32

Key Words: FAVAR, Stochastic Volatility, Uncertainty Shocks, Regional effects

\section{Introduction}

The recent financial crisis and ensuing recession have led to a renewed interest in the impact of uncertainty shocks. A number of proxies for uncertainty have been proposed in the recent literature and several papers use VAR based analyses to estimate the impact of uncertainty shocks (see for example Bloom (2009) and

*Queen Mary College. Email: h.mumtaz@qmul.ac.uk

$\dagger$ University of Copenhagen. E-mail: laura.sunder-plassmann@econ.ku.dk

$\ddagger$ University of Westminster. Email: A.Theophilopoulou@westminster.ac.uk 
Jurado et al. (2015) ). In addition, a growing DSGE based literature has documented the transmission mechanism of these shocks from a theoretical point of view (see for example Fernandez-Villaverde et al. $(2015))$

Overall, the empirical literature on this subject provides strong evidence that uncertainty shocks can have a significant adverse impact on the economy. For example, the analysis in Bloom (2009) suggests that a unit increase in uncertainty leads to a $1 \%$ decline in US industrial production and similar results are reported in related papers.

However, the estimates reported in these papers typically focus on the impact on aggregate data for the US. To our knowledge, the impact of aggregate uncertainty shocks at the level of US states has remained unexplored in the literature. This is surprising given the strong evidence that points to structural differences across US states. For example, the literature on the regional impact of monetary policy shocks (see Carlino and Defina (1998) amongst others), shows that states differ substantially in terms of the type and concentration of industry, the banking sector and the degree of credit frictions. These differences make it likely that their response to US-wide uncertainty shocks may also differ.

This paper attempts to fill this gap in the literature. We propose an extended factor augmented VAR (FAVAR) model that allows the estimation of a measure of macroeconomic uncertainty defined as the average time-varying volatility of real and financial shocks to the US economy. The proposed FAVAR model allows this measure of uncertainty to affect state-level real activity (as proxied by real income growth) while accounting for the possible impact of idiosyncratic uncertainty shocks. We find that the impact of uncertainty shocks differs markedly across states. The magnitude and persistence of the response is estimated to be the largest in Michigan, Indiana and Arizona, with income declining by about $0.3 \%$ and the impact persisting for more than three years. In contrast, the uncertainty shock has a smaller impact on states such as New York, Alaska and New Mexico. We then investigate which state-specific characteristics can explain the heterogeneous impact of uncertainty shocks. We find that income in states characterised by a larger share of manufacturing and construction industries, a higher share of small firms, a high fiscal deficit to expenditure ratio, a more volatile housing market and a smaller degree of labour market rigidities as proxied by 'right to work' laws appear to be affected to a larger degree by these shocks. In contrast, a higher share of mining/oil 
and gas industries and larger inter-governmental fiscal transfers mitigate the impact of uncertainty.

This paper makes two key contributions: First, it provides novel estimates of the heterogenous impact of uncertainty shocks across US states and highlights the factors that are important in explaining the crossstate differences. These results can be used to inform the choice of features when building theoretical models to explain the transmission of uncertainty shocks. For example, our analysis indicates that incorporating financial frictions and a fiscal sector may be important when in a model that is used to capture the effect of uncertainty. From a policy perspective, our analysis is relevant, as an understanding of regional differences in the response to shocks is a crucial ingredient in state-level policy making. Moreover, by using regional data from the US, the paper provides estimates of the impact of aggregate uncertainty shocks in a monetary union, thus making the results useful for policy-makers in such economic areas.

Second, the empirical model proposed in the paper builds upon existing VAR and FAVAR models by simultaneously allowing the estimation of time-varying uncertainty and the impact of aggregate uncertainty shocks on a large number of variables while controlling for the effect of idiosyncratic uncertainty shocks.

The paper is organised as follows: Sections 3 and 4 introduce the empirical model and discuss the estimation method. The results from the FAVAR model are presented in Section 5 , In section 6 we relate the state-level impulse responses to various characteristics of the states. Finally, section 7 concludes.

\section{Sources of heterogeneity in the response to uncertainty shocks}

Recent theoretical research on the transmission of uncertainty shocks has highlighted a number of factors that may affect the magnitude of the response of real activity to uncertainty shocks. As discussed below, these factors vary in intensity and importance across US states thus making it likely that the response to uncertainty shocks is heterogenous. 

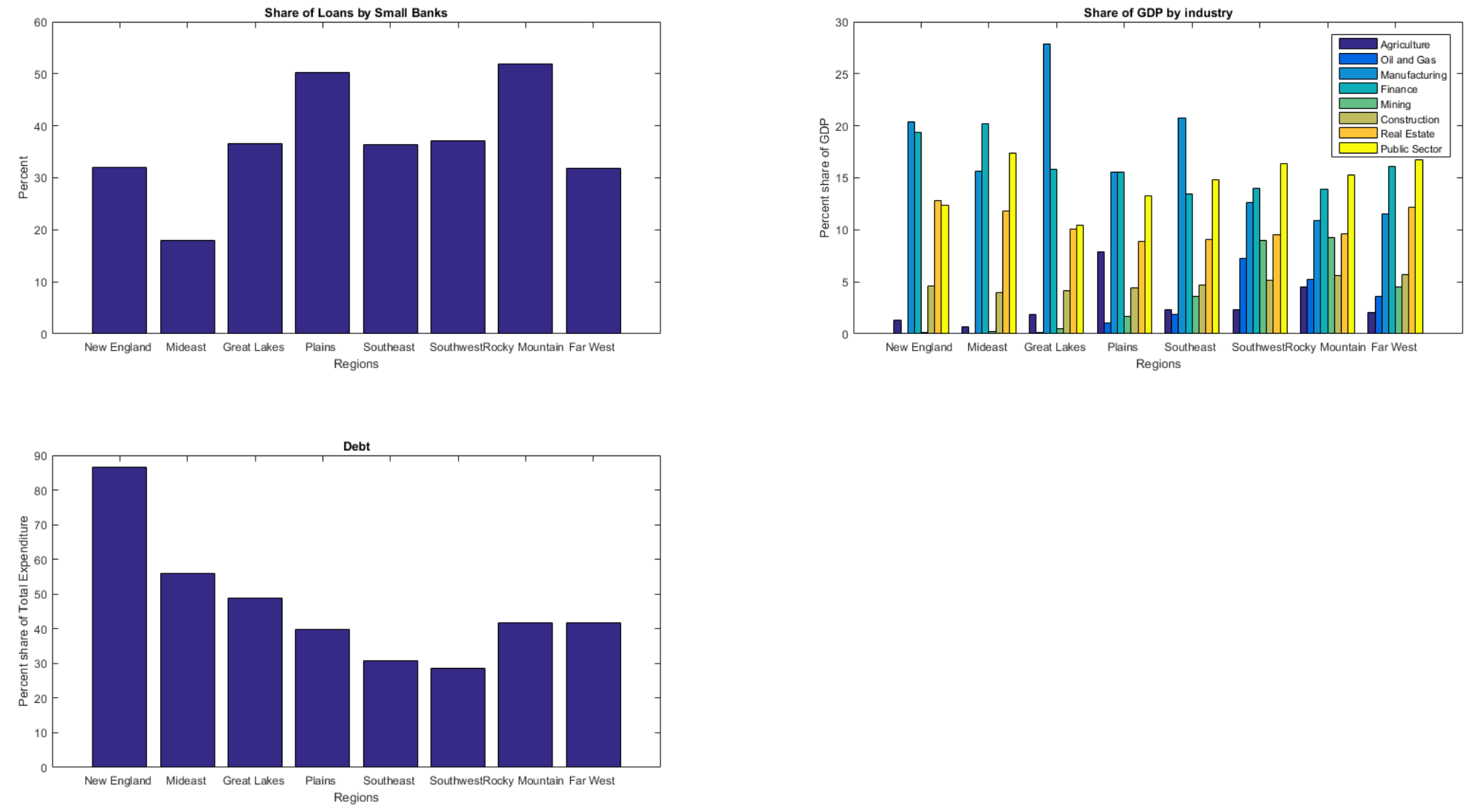

Figure 1: Top left panel: share of total loans made by small banks (average over the period 2001-2015). Top right panel: share of GDP by industry. (Average over the period 1963-2014). Bottom left panel: ratio of debt to total expenditure. (Average over the period 1992-2013). 


\subsection{Financial frictions}

A number of recent papers have argued that uncertainty affects the economy mainly through its impact on financial markets (see for example Christiano et al. (2014) and Gilchrist et al. (2014)). According to this view, if financial markets are subject to moral hazard, uncertainty shocks can affect investment through their impact on the external finance premium. This implies that the magnitude of the impact of these shocks may be linked to the intensity of financial frictions. Empirical evidence at the aggregate US level supporting this view has been presented recently in Alessandri and Mumtaz (2014) and Alfaro et al. (2016) who show that uncertainty shocks have a larger impact on real activity during periods of financial stress.

There is some evidence to suggest that the degree of financial frictions also differs markedly across states. Simple proxies that attempt to capture the intensity of these frictions appear to vary by state. For example, the top left panel of Figure 1 (based on an updated version of the data reported in Carlino and Defina (1998) ) shows the proportion of lending by small banks, where these are defined as those below the 90 th percentile in terms of assets. As is well known from the work of Kashyap and Stein (1995), the size of banks may affect their ability to finance their lending with larger banks expected to have access to more sources of funding. Figure 1 shows that the proportion of lending varies substantially across US regions. This provides prima facie evidence that some states may face a higher degree of credit frictions. A similar picture is suggested by measures of the 'broad credit channel' which emphasizes the vulnerability of small firms to information asymmetries problems. That is, the importance of small firms also varies substantially across regions with these establishments providing the largest share of employment in the Far West and Rocky Mountain region. In addition, it is likely that the structure of housing markets varies substantially across states, with these differences possibly contributing to heterogenous behaviour of agents in response to uncertainty shocks.

\subsection{Industry composition}

If uncertainty shocks have a large impact on the financial markets, they are likely to affect states with a heavier concentration of the financial and real-estate sector. Similarly, the response of commodity prices (for e.g. oil) to an uncertainty shock may affect those states which are more exposed to these price fluctuations due to heavier concentration of oil and gas and mining industries. Moreover, as pointed out in Carlino and 
Defina (1998), the manufacturing industry might be more sensitive to changes in the short-term interest rate.

If uncertainty shocks affect interest rates (perhaps via the reaction function of the Fed), then the cumulative impact of these shocks may be larger in regions where manufacturing is more dominant. In top right panel of Figure 1, we plot the share of GDP accounted for by key industries within US regions. It is clear from the figure that industry concentration is quite heterogeneous. For example, manufacturing accounts for a large share in the Great Lakes region, finance is important in the Mid-East, agriculture in the Plains while the mining, oil and gas and construction are concentrated in the Far/South West and the Rocky Mountain regions.

\subsection{State-Level fiscal indicators}

As discussed in Owyang and Zubairy (2013), US states also differ substantially in terms of fiscal indicators. For example, the debt to total expenditure ratio is close to $80 \%$ in New England while being relatively low in the South East and South West regions (see Figure 1). There also appears to be some variation in welfare spending and tax revenue across regions. State-level differences in fiscal capacity may also contribute to heterogeneity in the response to uncertainty shocks. For example, the magnitude of the impact of uncertainty shocks may be affected by the level of support available for agents when faced with a drop in income or employment prospects. In addition, as noted by Carriere-Swallow and Cespedes (2013), fiscal policies may also influence the degree to which state-level credit frictions can amplify the impact of uncertainty.

\subsection{Labour market rigidities}

Heterogeneity in the degree of labour market rigidities across the US can also be an important determinant of the magnitude of the impact of uncertainty on state real activity. As emphasised in recent theoretical work on uncertainty shocks (see for e.g. Leduc and Liu (2012)), labour market frictions can play an important role in determining the magnitude of the effect of uncertainty shocks on employment. If labour markets are

rigid, the impact of a decline in aggregate demand after an uncertainty shock may be magnified if delays in hiring and firing reduce the job-finding rate. On the other hand, a more rigid labour market may imply that the initial negative impact of uncertainty shocks is mitigated to a degree. 
In summary, there are a number of reasons to suggest that the impact of uncertainty shocks is heterogenous across US states. In the sections below, we first estimate the response of real income in each state to this shock. We then investigate if the differences in the response across states can be explained by some of the factors discussed above.

\section{Empirical model}

In this section we propose an empirical model that can be used to extract a measure of US-wide uncertainty while simultaneously allowing the estimation of the impact of uncertainty shocks on aggregate and state-level US variables. The core of this empirical model is the following vector autoregression:

$$
F_{t}=c+\sum_{j=1}^{P} \beta_{j} F_{t-j}+\sum_{j=1}^{J} \gamma_{j} \ln \lambda_{t-j}+\tilde{e}_{t}
$$

where $F_{t}$ is a set of unobserved common factors described below that effectively summarise the state of the US economy and capture the co-movement in state-level data. As in Cogley and Sargent (2005), the covariance matrix of the residuals is defined as:

$$
\Omega_{t}=A^{-1} H_{t} A^{-1^{\prime}}
$$

where $A$ is lower triangular. Therefore the orthogonalised shocks to $F_{t}$ are given as $e_{t}=A \tilde{e}_{t}$. Following Carriero et al. (2016), the volatility of these shocks $e_{t}$ is assumed to be:

$$
\begin{aligned}
H_{t} & =\lambda_{t} S \\
S & =\operatorname{diag}\left(s_{1}, . ., s_{N}\right)
\end{aligned}
$$

The common variance $\lambda_{t}$ evolves as an $\operatorname{AR}(1)$ process:

$$
\ln \lambda_{t}=\alpha+\beta \ln \lambda_{t-1}+Q^{1 / 2} \eta_{t}
$$


and the diagonal elements of $S$ are scaling factors.

The factors $F_{t}$ are linked to the observed data $X_{i t}$ via the following observation equation:

$$
X_{i t}=B_{i} F_{t}+\sum_{k=1}^{K} \rho_{k, i} \ln h_{i t-k}+v_{i t}
$$

As described below, $X_{i t}$ contains both aggregate US data covering real activity, inflation and the financial sector and real personal income for each state. The idiosyncratic shock is assumed to be heteroscedastic

$$
v_{i t}=R_{t}^{1 / 2} \varepsilon_{i t}
$$

with $R_{t}=\operatorname{diag}\left(h_{1 t}, . . h_{N t}\right)$ and

$$
\ln h_{i t}=a_{i}+b_{i} \ln h_{i t-1}+q_{i}^{1 / 2} n_{i t}
$$

The FAVAR model described by equations 1 to 6 has a number of distinctive features. First, the model allows for time-variation in the volatility of idiosyncratic errors $v_{i t}$ and in the volatility of shocks to the common components $e_{t}$. The time-varying volatility of $v_{i t}$ captures changes in the variance of idiosyncratic shocks and accounts for variable specific features such as measurement error. On the other hand, $\lambda_{t}$ is the average volatility of shocks to the common components $F_{t}$. Given that $F_{t}$ represents common developments in macroeconomic, financial and state-level data included in $X_{i t}$, the disturbances $e_{t}$ represent US level aggregate shocks 11 We interpret $\lambda_{t}$, the variance of this unpredictable component of $F_{t}$ as a measure of economy-wide uncertainty and $\eta_{t}$ as the uncertainty shock. As we show below, this specification produces estimates of uncertainty that are plausible from a historical perspective and compares favourably to semiparametric measures of uncertainty recently suggested in the literature (see Jurado et al. (2015)).

The volatility in mean formulation of equation 1 implies that shocks to $\lambda_{t}$ have an impact on the variables included in $X_{i t}$. We can therefore estimate the response of these variables to uncertainty shocks. Note that this estimated response is net of the impact of idiosyncratic volatility as the observation equation 4 allows $\ln h_{i t}$ to enter as a regressor ${ }^{2}$ For the state-specific variables of interest, this implies that we account for the

\footnotetext{
${ }^{1}$ These shocks represent disturbances that, for example, affect aggregate variables like GDP growth and have an impact on real income growth in all states.

${ }^{2}$ In a recent contribution, Shoag and Veuger (2016) construct measures of state-specific policy uncertainty using textual
} 
possible impact of state level uncertainty as partly captured by $h_{i t}$.

The common factors $F_{t}$ capture the co-movement among the variables included in the panel. In particular, they account for the relationship between state-specific series and the correlation of state data with aggregate US data. While the FAVAR model does not explicitly model spill-overs across states, it accounts for crossstate relationships via $F_{t} 3^{3}$ Thus, the estimated responses of state-specific variables to aggregate uncertainty shocks reflect any indirect impact of these shocks that is transmitted via cross-state channels.

\subsection{Relation with the existing literature}

The model presented in equations 2 and 3 is designed for the aim of estimating the response of state-level variables to aggregate uncertainty shocks and thus incorporates some unique features relative to models proposed in previous papers for estimating the effect of this shock.

While the stochastic volatility in mean specification is employed by several recent papers (see Mumtaz and Zanetti (2013), Mumtaz and Theodoridis (2015), Mumtaz and Surico (2013), Mumtaz and Theodoridis (2014) and Alessandri and Mumtaz (2014)), the model proposed in the current paper has two distinguishing features: First, it incorporates information from aggregate and state-level data in the estimation of the measure of uncertainty. Secondly, it accounts for the possible presence of idiosyncratic uncertainty shocks. This feature is especially important when the impact of uncertainty shocks on state-level series is considered. As noted above, our formulation captures the impact of aggregate uncertainty net of $h_{i t}$, the proxy for state-specific uncertainty shocks.

This latter feature also distinguishes our model from a possible alternative approach that would use existing measures of US economic uncertainty in a large VAR or a FAVAR model. For example, one may consider using the following FAVAR to model $X_{i t}$ :

$$
\begin{aligned}
X_{i t} & =B_{i} \tilde{F}_{t}+\tilde{v}_{i t} \\
Z_{t} & =c+\sum_{j=1}^{P} \beta_{j} Z_{t-j}+\tilde{\Omega}^{1 / 2} \tilde{e}_{t}
\end{aligned}
$$

analysis and relate it to unemployment outcomes during the Great Recession.

${ }^{3}$ In other words, while the model is suited to estimating the impact of aggregate uncertainty shocks, a more complex structure is required if interest centers on estimating the impact of state $i$ uncertainty shocks on the economy of state $j$. In the FAVAR, such shocks are 'filtered out' by accounting for the impact of $h_{i t}$ in the observation equation. 
where $\tilde{F}_{t}$ denotes a set of unobserved factors, $B_{i}$ are factor loadings and $Z_{t}=\left[\tilde{F}_{t}, \ln \varpi_{t}\right]$ with $\varpi_{t}$ denoting an existing measure of economic uncertainty for the US (for e.g. the measure of uncertainty estimated by Jurado et al. (2015)) . Then, given the model parameters and a decomposition of $\tilde{\Omega}$, one can easily estimate the response of state-specific series in $X_{i t}$ to shocks to the equation for $\ln \varpi_{t}$. While this approach is simple and easy to implement, it does not account directly for the possibility that state-specific series may be affected by both aggregate uncertainty and uncertainty shocks specific to the state in question. One may augment the observation equation in expression 7 with a measure of uncertainty specific to each series to alleviate this problem. Our proposed model, attempts to do exactly this by incorporating the impact of $\ln h_{i t}$. We show in the sensitivity analysis below that while the simpler specification in equation 7 produces a cross-state pattern of responses to uncertainty that are very similar to the benchmark model, the magnitude can be quite different possibly reflecting the omission of the effect of idiosyncratic uncertainty shocks.

\section{Estimation and model specification}

The model defined in equation 1 and 4 is estimated using an MCMC algorithm. In this section we summarise the key steps of the algorithm and provide the details in the technical appendix $4^{4}$ The appendix also presents the details on the prior distributions which are standard.

As noted in Bernanke et al. (2005), the FAVAR model is subject to rotational indeterminancy of the factors and factor loadings. Following Bernanke et al. (2005), we impose a normalisation under which the first $K \times K$ block of the factor loadings is fixed to an identity matrix.

The MCMC algorithm consists of the following steps:

1. Conditional on a draw for the stochastic volatility $\lambda_{t}$, the factors $F_{t}$, the matrix $A$, and the variances $S$, equation (1) represents a VAR model with a known form of heteroscedasticity. The algorithm of Carter and Kohn (2004) is used to draw the VAR coefficients from their conditional posterior density while accounting for the time-varying variance via the Kalman filter.

2. Conditional on a draw for the factors $F_{t}$, the stochastic volatility $\lambda_{t}$ and $S$ the non-unity and non-zero elements of $A$ are drawn using methods for linear regressions with heteroscedasticity.

\footnotetext{
${ }^{4}$ The appendix presents a small Monte-Carlo experiment that shows that the algorithm displays a satisfactory performance.
} 
3. Given $A$ and $\lambda_{t}$, the elements of $S$ have an inverse Gamma posterior and these parameters can be easily simulated from this distribution.

4. Conditional on $\lambda_{t}$, the constant $\alpha$, autoregressive parameter $F$ and variance $Q$ can be drawn using standard results for linear regressions.

5. Conditional on a draw for the factors $F_{t}$ and the volatilities $h_{i t}$ methods for heteroscedastic linear regressions can be used to draw the factor loadings $B_{i}$ and the coefficients $\rho_{k, i}$.

6. Conditional on a draw for the factors $F_{t}$ and the factor loadings $B_{i}$, the coefficients $\rho_{k, i}$ and the parameters of the transition equations 6 , the stochastic volatilities $h_{i t}$ can be drawn using a date by date independence Metropolis step as described in Cogley and Sargent (2005) and Jacquier et al. (1994) (see also Carlin et al. (1992)). The same algorithm is used to draw the common volatility $\lambda_{t}$.

7. Given the parameters of the observation equation 4 and the transition equation 1 , the Carter and Kohn (2004) algorithm is used to draw from the conditional posterior distribution of the factors $F_{t}$.

In the benchmark specifications, we use 200,000 replications and base our inference on the last 5,000 replications. The recursive means of the retained draws (see technical appendix) show little fluctuation providing support for convergence of the algorithm.

\subsection{Model specification}

We consider models with 3 to 7 factors and select the model which minimises the Bayesian Deviance Information Criterion (DIC). Introduced in Spiegelhalter et al. (2002), the DIC is a generalisation of the Akaike information criterion - it penalises model complexity while rewarding fit to the data. As shown in the appendix, the DIC can be calculated as $D I C=\bar{D}+p_{D}$ where $\bar{D}$ measures goodness of fit and $p_{D}$ approximates model complexity. A model with a lower DIC is preferred. Table 1 shows that the $D I C$ is minimised for the model with 3 factors. Therefore, we select 3 factors in our benchmark model.

In the benchmark model, the lag length $P$ and $J$ is set to 4 . We show in the technical appendix that the results do not change substantially for alternative specifications of the model. In particular, a model with 5 factors produces results similar to benchmark. 


\begin{tabular}{ll}
\hline & $D I C$ \\
3 factors & 36652.03 \\
4 factors & 38096.85 \\
5 factors & 41663.51 \\
6 factors & 65216.41 \\
7 factors & 72648.66 \\
\hline
\end{tabular}

Table 1: Model Comparison via DIC. Best fit indicated by lowest DIC

\subsection{Data}

The dataset is quarterly and runs from 1950Q1 to 2014Q1. The panel contains 91 aggregate variables and the real income for each of the 50 US states and the District of Columbia. Non-stationary variables are log-differenced. Finally, the series are de-meaned. The 91 aggregate variables cover real activity, prices, short-term and long term interest rates, various corporate bond spreads and series on money and credit growth. Data on stock market variables, commodity prices and exchange rates is included. In summary, the aggregate dataset covers the key sectors of the US economy and incorporates a wide range of information. The technical appendix provides a list of the series included in the panel.

\section{Empirical results}

\subsection{The Measure of Uncertainty}

Figure 2 plots the posterior median and the $68 \%$ bands for $\lambda_{t}$. The figure also plots the uncertainty measure recently proposed in Jurado et al. (2015) for comparison. The measure of uncertainty is high during the early and the mid-1970s reaching a large peak during the early 1980s. The mid-1980s saw the onset of the great moderation and $\lambda_{t}$ declined and remained low until the recession during the early 1990s and then during the early 2000s. The recent financial crisis saw a substantial increase in uncertainty with the level of $\lambda_{t}$ during 2008/2009 matching the volatility seen during the 1970s and the early 1980s. 


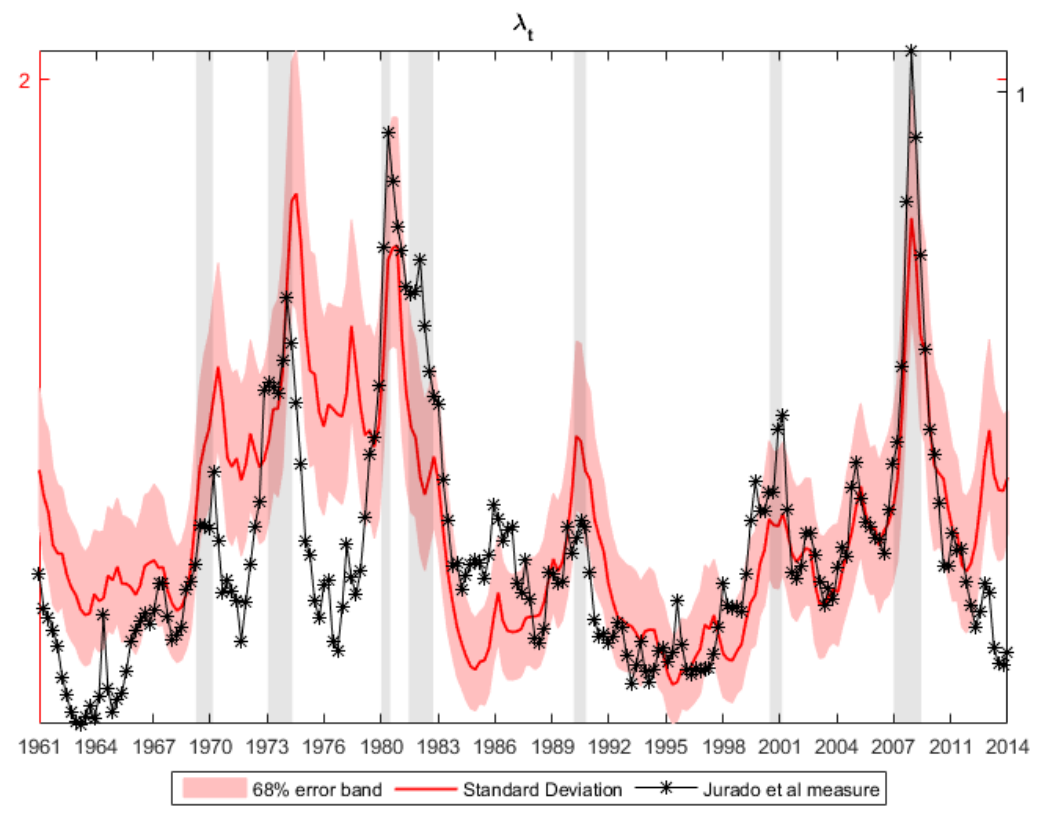

Figure 2: Estimated Volatility $\lambda_{t}$. The posterior estimates of $\lambda_{t}$ are compared with the measure of uncertainty reported in Jurado et al. (2015). The shaded areas represent the NBER recession dates. 

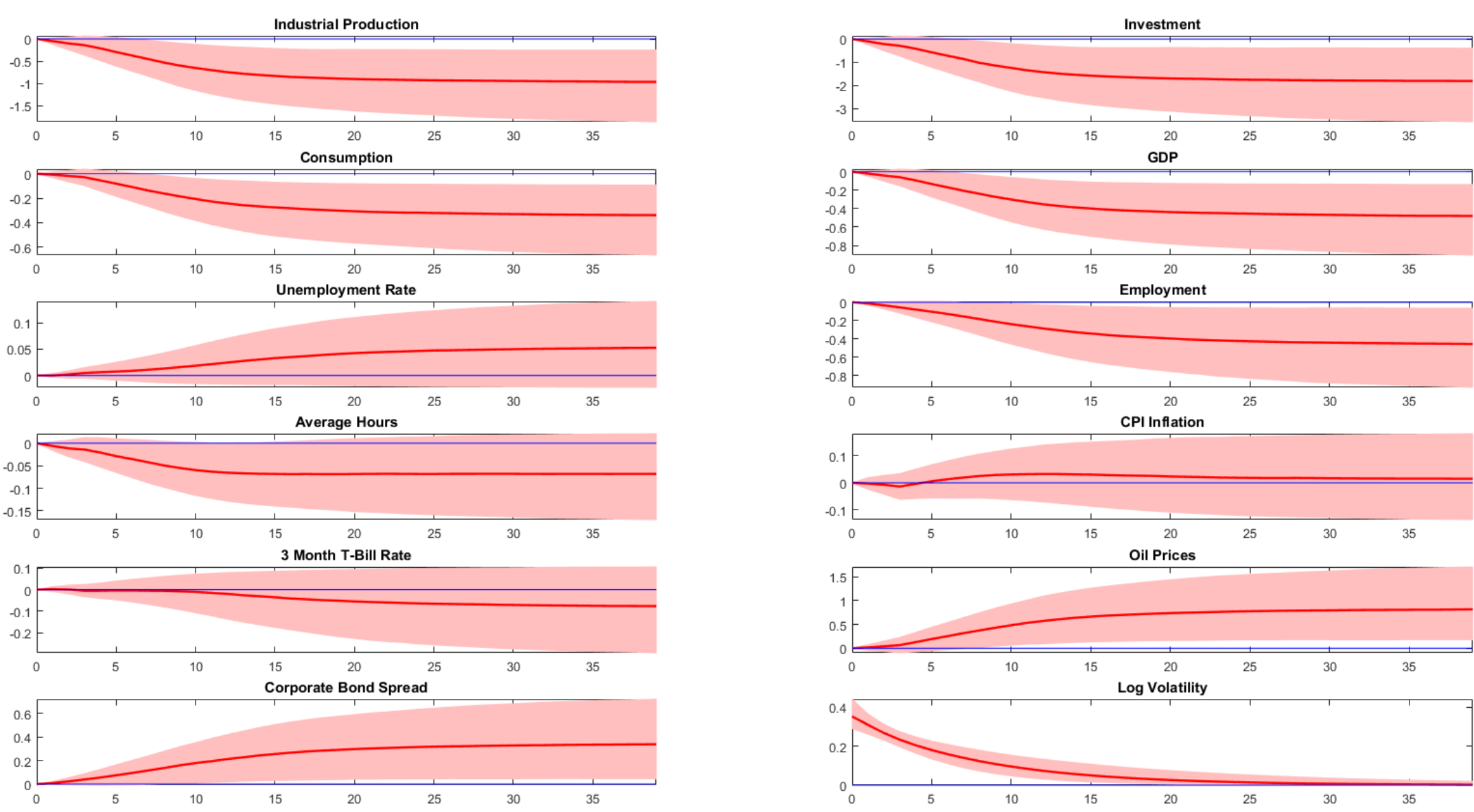

Figure 3: Cumulated response of aggregate variables to uncertainty shocks 
It is interesting to note that the estimate of $\lambda_{t}$ is highly correlated with the measure of uncertainty proposed in Jurado et al. (2015). This reflects the fact that the underlying method of capturing uncertainty has a number of similarities with the calculation in Jurado et al. (2015). The uncertainty measure in Jurado et al. (2015) is the average time-varying variance in the unpredictable component of a large set of real and financial time-series. The volatility specification in equations 2 and 3 has a similar interpretation as it attempts to capture the average volatility in the shocks to $F_{t}$ where the factors summarise real and financial conditions 5 However, as discussed above, the model used in this paper offers a distinct advantage for the purpose of estimating the impact of uncertainty shocks - it allows one to recover the responses to overall uncertainty shocks while 'filtering out' the effects of idiosyncratic uncertainty and measurement error captured by $h_{i t}$.

In figure 3 we consider how innovations to $\lambda_{t}$ affect aggregate variables. A one standard deviation uncertainty shock results in a decline in real activity with a fall in production, hours, investment, consumption, employment and GDP and an increase in the unemployment rate. Note that the magnitude of the decline in industrial production is in line with the results reported in Bloom (2009), while the employment response is broadly similar to the fall in this variable generated by a one standard deviation shock to uncertainty in the VAR model of Jurado et al. (2015). These estimates are consistent with the conventional view on the impact of uncertainty shocks on real activity ${ }^{6}$ The response of inflation is imprecisely estimated but suggests that the total impact is positive at the two year horizon providing some support to the 'pricing bias' channel postulated in Fernandez-Villaverde et al. (2015) and discussed in Mumtaz and Theodoridis (2015)-in other words, when the economy is characterised by price and wage rigidity, inflation rises in the face of uncertainty because forward looking agents bias their pricing decision upwards in order to avoid supplying goods when demand and costs are high. The uncertainty shock is associated with a deterioration in financial conditions and the corporate bond spread increases. In addition, oil prices rise by about $0.2 \%$ in response to an increase in uncertainty.

\footnotetext{
${ }^{5}$ Note that the estimate of $\lambda_{t}$ has a correlation of 0.45 with the index of Baker et al. $(2016)$ which tries to measure uncertainty associated with economic policy.

${ }^{6}$ We find little evidence of the rebound in real activity reported by Bloom (2009). As discussed in Jurado et al. (2015), this feature of the responses appears to be related to HP-filtered data employed by that paper.
} 


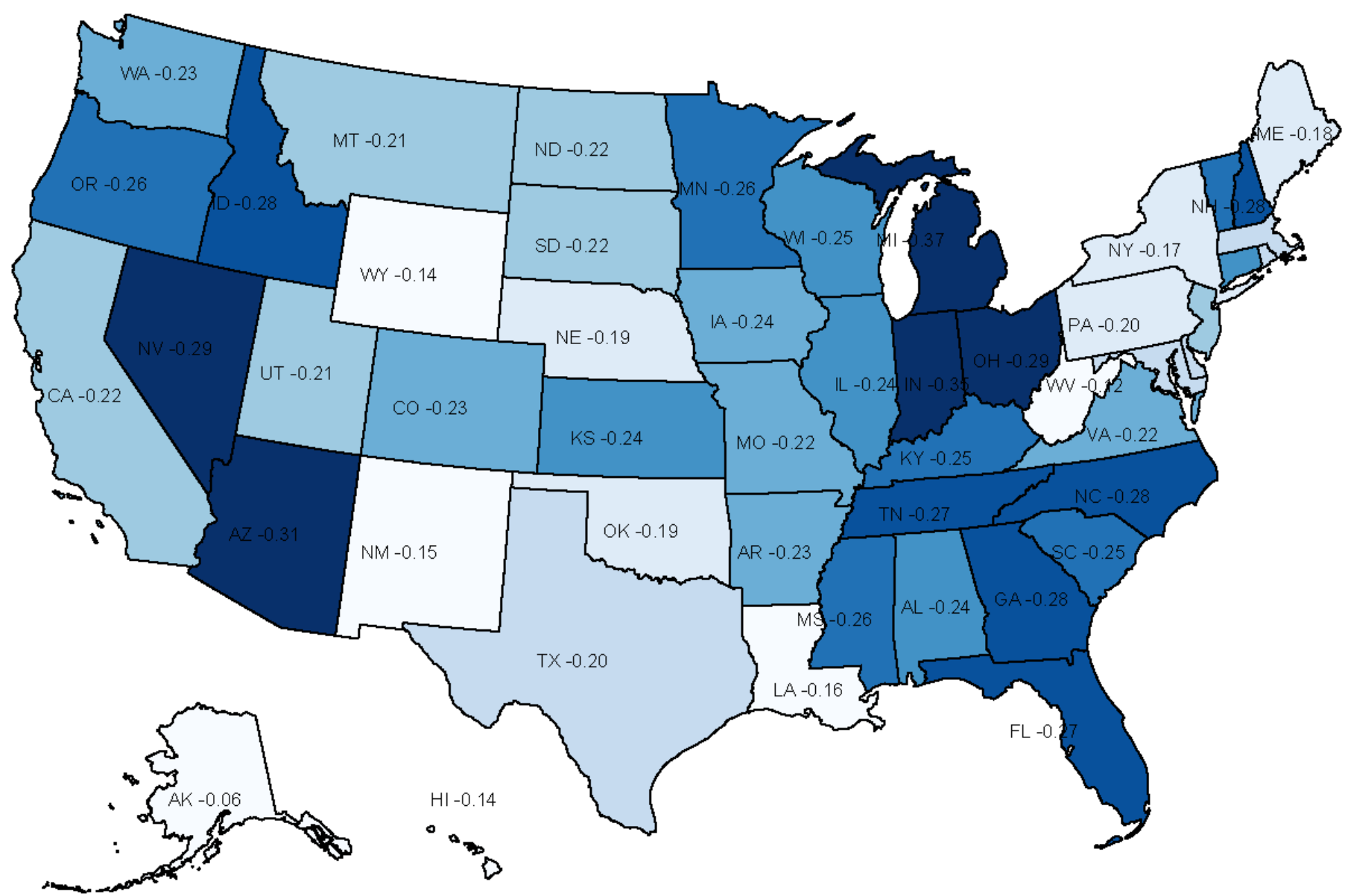

Figure 4: Cumulated response of state-level income to a 1 standard deviation uncertainty shock at the 2 year horizon. The posterior median estimates are reported for each state with darker colours reflecting a stronger response. 


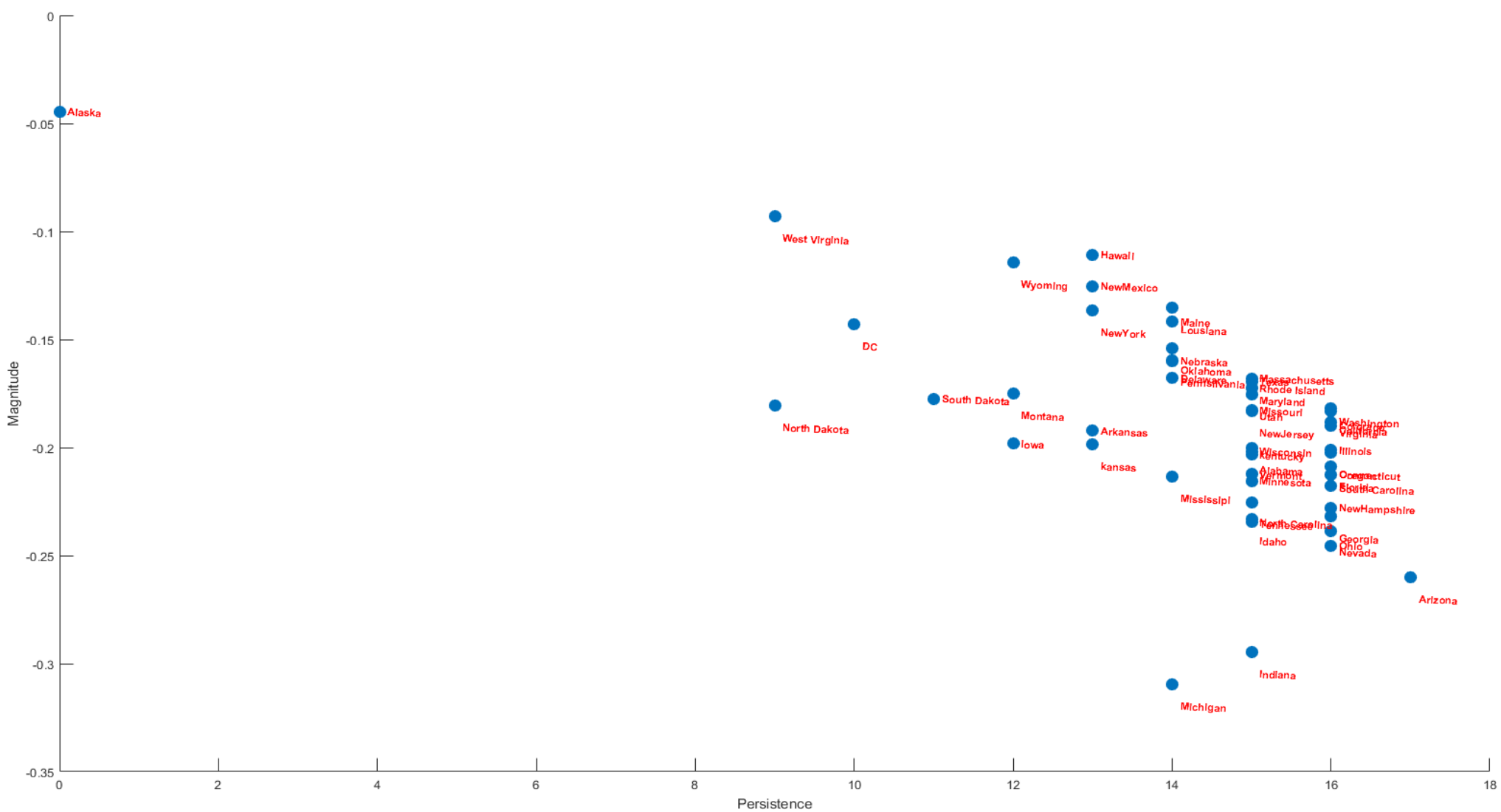

Figure 5: The relationship between magnitude and persistence of the response of real income in each state 


\subsection{State-Level response of uncertainty shocks}

In this section we consider the response the response of real income growth to uncertainty shocks across US states and investigate the presence of heterogeniety at the state level 7 The map in Figure 4 presents the posterior median estimate of the cumulated response of state-level real income to a one standard deviation uncertainty shock at the two year horizon. Stronger responses are reflected by darker colours. Real income declines in all states in response to an increase in US wide uncertainty, with the median decline estimated at $0.18 \%$. The magnitude of the decline is largest in Michigan, Indiana and Arkansas with income falling by about $0.26 \%$ to $0.3 \%$. The response in the majority of the states lies within the range $-0.15 \%$ and $-0.25 \%$. States with the lowest response (i.e. larger than -0.15\%) include New York, Alaska and New Mexico.

Figure 5 shows that the persistence of the response to uncertainty shocks is larger in states where the impact is estimated to be of a higher magnitude. We measure the persistence by the number of quarters before the hypothesis of a zero response cannot be rejected 8 In states such as Michigan, Arizona and Indiana, the effects of the uncertainty shock persist for longer than three years. In contrast, there is scant statistical evidence that the impact of the shock is persistent in states such as Alaska.

\section{Explaining the heterogeneity of state-level responses}

As discussed in section 2 cross-state differences in the response of income to uncertainty shocks can be driven by cross-state variations in financial and fiscal conditions, industry mix and the labour market. In this section we attempt to quantify these possible relationships by estimating regressions of the following form:

$$
\text { response }_{i}^{h}=\alpha+D_{j}+\beta X_{i}+v_{i}
$$

where response $e_{i}^{h}$ denotes the h-period cumulated response of state i's real income. $\alpha$ is an intercept while $D_{j}$ represents a set of dummies defined for the BEA regions. The regressors $X_{i}$ include proxies that attempt to capture the role of the state-specific factors discussed above.

\footnotetext{
${ }^{7}$ We have also estimated a version of the model using state-level employment instead of real income. The pattern of statespecific responses is very similar to the benchmark. See technical appendix.

${ }^{8}$ The $68 \%$ posterior error bands are used to calculate the persistence. For states where the error bands include a zero response at more than one point on the horizon, the last instance is used as the persistence measure.
} 
The first set of regressors that we consider account for heterogeneity in the structure of industry. We consider the share of the proportion of nominal state-level GDP accounted for by manufacturing, finance, real estate, agriculture, construction, mining, oil and gas and the government.

The next set of regressors attempts to account for the degree of financial frictions. Following Carlino and Defina (1998), we include the percentage of each state's loans that are made by small banks. To proxy for the broad credit channel the proportion of small firms in terms of employment are included with establishments employing less than 250 workers categorised as small. In order to account for cross-state differences in the housing market we use the homeowner vacancy rate in the benchmark specification, but also consider the rental vacancy rate, the home ownership rate and the variance of these variables.

In order to capture the fiscal situation in each state we use a number of proxies. State-specific revenue is accounted for by including the share of inter-governmental revenue in the total. We attempt to capture variation in expenditure across states by using the proportion of expenditure on welfare and on subsidies. The budget situation is accounted for via the budget balance and debt as a share of expenditures.

Finally, we explore the role played by labour market rigidities. To proxy this, we include the degree of unionization in some of the specifications. In addition, we construct a dummy variable that takes the value of 1 for states where 'right to work' laws are in existence. These laws represent an attempt to provide the right to work to employees without the implicit or explicit requirement to join a union. We also consider the degree of business creation as an additional proxy in some of the specifications discussed below.

The source of this cross section data and the construction of the variables closely follows previous studies such as Carlino and Defina (1998) and Guisinger et al. (2015). Details on each variable are provided in the technical appendix to the paper. In the section below we present the results from our preferred specifications that retain the most important regressors from a statistical point of view. An extensive sensitivity analysis is presented in the technical appendix and discussed below. 


\begin{tabular}{|c|c|c|c|c|c|c|}
\hline & $\begin{array}{c}(1) \\
\text { IRF } 2 \mathrm{yr}\end{array}$ & $\begin{array}{c}(2) \\
\text { IRF } 2 \mathrm{yr}\end{array}$ & $\begin{array}{c}(3) \\
\text { IRF } 2 \mathrm{yr}\end{array}$ & $\begin{array}{c}(4) \\
\text { IRF } 2 y r\end{array}$ & $\begin{array}{c}(5) \\
\text { IRF } 2 \mathrm{yr}\end{array}$ & $\begin{array}{c}(6) \\
\text { IRF 1yr }\end{array}$ \\
\hline Manufacturing & $\begin{array}{c}-0.308^{* * *} \\
(0.084)\end{array}$ & $\begin{array}{c}-0.263^{* * *} \\
(0.077)\end{array}$ & $\begin{array}{c}-0.230^{* * *} \\
(0.075)\end{array}$ & $\begin{array}{c}-0.232^{* * *} \\
(0.079)\end{array}$ & $\begin{array}{c}-0.379^{* * *} \\
(0.080)\end{array}$ & $\begin{array}{c}-0.163^{* * *} \\
(0.032)\end{array}$ \\
\hline Mining & $\begin{array}{l}0.305^{* *} \\
(0.132)\end{array}$ & $\begin{array}{c}0.359^{* * *} \\
(0.122)\end{array}$ & $\begin{array}{c}0.399^{* * *} \\
(0.114)\end{array}$ & $\begin{array}{c}0.419^{* * *} \\
(0.089)\end{array}$ & $\begin{array}{c}0.475^{* * *} \\
(0.099)\end{array}$ & $\begin{array}{c}0.177^{* * *} \\
(0.046)\end{array}$ \\
\hline Home vacancy rate & $\begin{array}{c}-3.940^{* * *} \\
(1.037)\end{array}$ & $\begin{array}{c}-3.447^{* * *} \\
(0.931)\end{array}$ & $\begin{array}{c}-4.243^{* * *} \\
(0.941)\end{array}$ & $\begin{array}{c}-3.611^{* * *} \\
(0.883)\end{array}$ & $\begin{array}{c}-2.742^{* * *} \\
(0.866)\end{array}$ & $\begin{array}{c}-0.889^{* *} \\
(0.359)\end{array}$ \\
\hline Right to work & & $\begin{array}{c}-0.024^{* *} \\
(0.010)\end{array}$ & $\begin{array}{c}-0.026^{* * *} \\
(0.009)\end{array}$ & $\begin{array}{c}-0.025^{* * *} \\
(0.009)\end{array}$ & $\begin{array}{c}-0.028^{* * *} \\
(0.009)\end{array}$ & $\begin{array}{c}-0.009^{* *} \\
(0.004)\end{array}$ \\
\hline Small firms $(<250)$ & & & $\begin{array}{c}-0.277^{*} \\
(0.140)\end{array}$ & $\begin{array}{c}-0.336^{* *} \\
(0.137)\end{array}$ & $\begin{array}{c}-0.443^{* * *} \\
(0.136)\end{array}$ & $\begin{array}{c}-0.160^{* * *} \\
(0.056)\end{array}$ \\
\hline Budget deficit & & & & $\begin{array}{c}-0.119^{*} \\
(0.065)\end{array}$ & $\begin{array}{c}-0.132^{* *} \\
(0.063)\end{array}$ & $\begin{array}{c}-0.055^{* *} \\
(0.027)\end{array}$ \\
\hline Intergov't transfers & & & & $\begin{array}{c}0.194^{* * *} \\
(0.068)\end{array}$ & $\begin{array}{c}0.193^{* *} \\
(0.073)\end{array}$ & $\begin{array}{c}0.082^{* * *} \\
(0.029)\end{array}$ \\
\hline Construction & & & & & $\begin{array}{c}-2.421^{* * *} \\
(0.701)\end{array}$ & $\begin{array}{c}-1.036^{* * *} \\
(0.287)\end{array}$ \\
\hline Observations & 51 & 51 & 51 & 50 & 50 & 50 \\
\hline Adjusted $R^{2}$ & 0.564 & 0.597 & 0.613 & 0.667 & 0.719 & 0.680 \\
\hline
\end{tabular}

Table 2: Cross-sectional regression results 


\subsection{Benchmark results}

Table 2 shows the results using our preferred specifications. The first five columns of the table refer to the baseline case which uses the impulse response of income cumulated at the two year horizon as the dependent variable. The final column of the table considers the response cumulated at the one-year horizon as the dependent variable.

The first column of the table relates the estimated responses to variables accounting for the structure of industry in each state. Here we present the result for the industry variables that displayed a robust relationship with the uncertainty responses across a variety of specifications. This additional robustness analysis is presented in Table 1 in the on-line technical appendix. The results in the first column of Table 2 clearly show that the coefficients on the share of manufacturing and mining industries are highly significant. The negative coefficient on the share of manufacturing suggests that states with a higher concentration of manufacturing also experience a larger drop in real income in the face of uncertainty shocks. In contrast, a larger ratio of mining industries in GDP is associated with a smaller negative response. As shown in the technical appendix (see Table 1 in the appendix), very similar results are obtained when the share of mining in GDP is replaced by the share of oil and gas, a sub-category of mining in the classification of industries. As shown in figure 3, the uncertainty shock results in an increase in the price of some commodities like oil. This may help to ameliorate the negative effects of uncertainty in states where a larger share of GDP is accounted for by such industries.

Column two of Table 2 shows that the coefficient on the home vacancy rate is significant and negative. States with a larger home vacancy rate experience a larger drop in income in the face of uncertainty shocks. This suggest that a higher vacancy rate may signal the inability or unwillingness of agents to absorb negative shocks. Similar results are obtained if the home vacancy rate is replaced by the standard deviation of this variable or if the rental vacancy rate is considered (see Table 5 in the technical appendix). The volatility of the home ownership rate also has a negative relationship with response to uncertainty but the level of this variable appears to be unimportant. Column two of Table 2 also introduces the right to work dummy variable. States that have enacted this legislation are associated with a stronger drop in income in the face of uncertainty shocks. This may suggest that the labour market in these states is less subject to rigidities 
that may cushion the impact of uncertainty shocks in the short-run. We show in the technical appendix (see Table 4) that while the sign of the coefficient on the degree of unionisation is consistent with these results, the estimate is imprecise. Similarly, the estimated impact of business creation is not robust across specifications.

The third column of Table 2 shows that the coefficient on the share of small firms in total employment is negative and significant at the $10 \%$ level. This provides some evidence to suggest that the broad credit channel may play a role in the transmission of uncertainty shocks. Results based on other proxies for financial frictions are weaker. Table 2 in the technical appendix shows that the coefficients on lending by small banks is insignificant across a variety of specifications.

Column four of Table 2 considers fiscal indicators that appear to have a robust relationship with the dependent variable. States with a larger budget deficit as a share of expenditure are associated with a larger negative response of real income to uncertainty shocks. On the other hand, a larger proportion of inter-governmental transfers appear to have a positive effect-a smaller negative response of real income is associated with states with a larger ratio of inter-governmental transfers to total expenditures. These results do not change if the share of construction in GDP is added to the model (Column five of Table 2). It is interesting to note that states with a larger share of construction also appear to be associated with a larger negative effect of uncertainty. In the final column of Table 2 we consider if the results are robust to the horizon of the impulse response used to contruct the dependent variable. This specification uses the impulse response cumulated over four quarters. The results suggest that while the magnitude of the estimated coefficients is somewhat smaller, the sign and significance are broadly similar to the benchmark case.

As discussed in section 3.1 above, we also estimate a simple FAVAR that uses the Jurado et al. (2015) measure of uncertainty and estimate the impact of innovations to this measure on state-level income growth. As shown in Figure 4 in the technical appendix, this produce a cross-section of state-level income responses that has a correlation of 0.86 with the benchmark estimates reported in Figure 4. Moreover, when the responses estimated via the simpler model are used in the main cross-section regression (see Table 7 in the technical appendix), the sign of the coefficients is the same as in the benchmark case. Thus, this 
alternative model delivers implications for the heterogenous impact of uncertainty shocks which are close to our benchmark results. The magnitude of the responses obtained from the simple model are larger, however and this also affects the size of the coefficients in the cross-section regression. As argued in section 3.1 , this may reflect the fact that unlike the benchmark FAVAR model, the simple FAVAR does not account for the possible impact of state-level uncertainty shocks and may suffer from statistical biases.

In summary, the benchmark estimates and the detailed robustness checks presented in the technical appendix suggest the following results: (1) States with a heavy concentration of manufacturing and construction industries experience a larger drop in income when hit by an uncertainty shock. In contrast, states with mining as a larger proportion of GDP appear to be affected less by this shock. (2) The fiscal position of states plays an important role - a larger budget deficit is associated with a more negative response of state-level income to uncertainty shocks while the proportion of inter-governmental transfers appear to ameliorate the impact of uncertainty. (3) Income in states with a more volatile housing market declines by a larger amount in the face of uncertainty shocks. (4) States that have enacted right to work legislation are associated with a larger impact of uncertainty shocks. (5) Uncertainty shocks reduce income by more in states where the share of small firms is larger suggesting that financial frictions may be important.

\section{Conclusions}

This paper uses an extended factor augmented VAR (FAVAR) model to study the impact of uncertainty shocks on the real income of US states. We find that the impact of uncertainty shocks is heterogenous. The magnitude and persistence of the response is estimated to be the largest in Michigan, Indiana and Arizona. In contrast, the uncertainty shock has a smaller impact on income in states such as New York, Alaska and New Mexico. Cross-sectional regressions relating the state-specific impulse responses to state features suggest that income declines by more in states characterised by a larger share of manufacturing, agriculture and construction industries, higher fiscal deficit to expenditure ratio and home vacancy rate. States that have a higher share of mining industries and larger inter-governmental fiscal transfers appear to be affected 
less by uncertainty.

These results highlight the importance of industrial structure and concentration for the transmission of uncertainty shocks. In future work, It would be interesting to explore how these features can be introduced into theoretical models used to study the impact of uncertainty. It would also be useful to explore, in detail, the interaction between uncertainty shocks and prices of commodities such as oil and the role played by commodity prices in propagating the effect of uncertainty at an international level.

\section{References}

Alessandri, Piergiorgio and Haroon Mumtaz, 2014, Financial Regimes and Uncertainty Shocks, Working Papers 729, Queen Mary University of London, School of Economics and Finance.

Alfaro, Ivan, Nicholas Bloom and Xiaoji Lin, 2016, The Finance-Uncertainty Multiplier, Working paper, Stanford University.

Baker, Scott R, Nicholas Bloom and Steven J Davis, 2016, Measuring Economic Policy Uncertainty, The Quarterly Journal of Economics .

Bernanke, B. S., J. Boivin and P. Eliasz, 2005, Measuring the Effects of Monetary Policy: A Factor Augmented Vector Autoregressive (FAVAR) Approach, Quarterly Journal of Economics 120, 387-422.

Bloom, Nicholas, 2009, The Impact of Uncertainty Shocks, Econometrica 77(3), 623-85.

Carlin, Bradley P., Nicholas G. Polson and David S. Stoffer, 1992, A Monte Carlo Approach to Nonnormal and Nonlinear State-Space Modeling, Journal of the American Statistical Association 87(418), 493-500.

Carlino, Gerald and Robert Defina, 1998, The Differential Regional Effects Of Monetary Policy, The Review of Economics and Statistics 80(4), 572-587.

Carriere-Swallow, Yan and Luis Felipe Cespedes, 2013, The impact of uncertainty shocks in emerging economies, Journal of International Economics 90(2), 316 - 325.

Carriero, Andrea, Todd E. Clark and Massimiliano Marcellino, 2016, Common Drifting Volatility in Large Bayesian VARs, Journal of Business $\&$ Economic Statistics $\mathbf{0}(\mathrm{ja})$, 00-00. 
Carter, C and P Kohn, 2004, On Gibbs sampling for state space models, Biometrika 81, 541-53.

Christiano, Lawrence J., Roberto Motto and Massimo Rostagno, 2014, Risk Shocks, American Economic Review 104(1), 27-65.

Cogley, T. and T. J. Sargent, 2005, Drifts and Volatilities: monetary policies and outcomes in the Post WWII U.S., Review of Economic Dynamics 8, 262-302.

Fernandez-Villaverde, Jesús, Pablo Guerrón-Quintana, Keith Kuester and Juan Rubio-Ramírez, 2015, Fiscal Volatility Shocks and Economic Activity, American Economic Review 105(11), 3352-84.

Gilchrist, Simon, Jae W. Sim and Egon ZakrajÅąek, 2014, Uncertainty, Financial Frictions, and Investment Dynamics, Working Paper 20038, National Bureau of Economic Research.

Guisinger, Amy Y., Ruben Hernandez-Murillo, Michael T. Owyang and Tara M. Sinclair, 2015, A State-Level Analysis of OkunŠs Law, Working Paper 1523, Federal Reserve Bank of Cleveland.

Jacquier, E, N Polson and P Rossi, 1994, Bayesian analysis of stochastic volatility models, Journal of Business and Economic Statistics 12, 371-418.

Jurado, Kyle, Sydney C. Ludvigson and Serena Ng, 2015, Measuring Uncertainty, American Economic Review 105(3), 1177-1216.

Kashyap, Anil and Jeremy Stein, 1995, The impact of monetary policy on bank balance sheets, CarnegieRochester Conference Series on Public Policy 42(1), 151-195.

Leduc, Sylvain and Zheng Liu, 2012, Uncertainty shocks are aggregate demand shocks, Technical report.

Mumtaz, Haroon and Francesco Zanetti, 2013, The Impact of the Volatility of Monetary Policy Shocks, Journal of Money, Credit and Banking 45(4), 535-558.

Mumtaz, Haroon and Konstantinos Theodoridis, 2014, The Changing Transmission of Uncertainty shocks in the US: An Empirical Analysis, Working Papers 735, Queen Mary University of London, School of Economics and Finance. 
Mumtaz, Haroon and Konstantinos Theodoridis, 2015, The International Transmission OF Volatility Shocks: An Empirical Analysis, Journal of the European Economic Association 13(3), 512-533.

Mumtaz, Haroon and Paolo Surico, 2013, Policy Uncertainty and Aggregate Fluctuations, Working Papers 708, Queen Mary University of London, School of Economics and Finance.

Owyang, Michael T. and Sarah Zubairy, 2013, Who benefits from increased government spending? A statelevel analysis, Regional Science and Urban Economics 43(3), 445 - 464.

Shoag, Daniel and Stan Veuger, 2016, Uncertainty and the geography of the great recession, Journal of Monetary Economics pp. -.

Spiegelhalter, David J., Nicola G. Best, Bradley P. Carlin and Angelika Van Der Linde, 2002, Bayesian measures of model complexity and fit, Journal of the Royal Statistical Society: Series B (Statistical Methodology) 64(4), 583-639. 


\title{
The State-Level Impact of Uncertainty Shocks (On-line Technical Appendix. Not for Publication)
}

\author{
Haroon Mumtaz* $\quad$ Laura Sunder-Plassmann ${ }^{\dagger} \quad$ Angeliki Theophilopoulou ${ }^{\ddagger}$
}

September 4, 2017

\section{Model}

The FAVAR model is defined as

$$
\begin{aligned}
X_{i t} & =B_{i} F_{t}+\sum_{k=1}^{K} \rho_{k, i} \ln h_{i t-k}+v_{i t} \\
F_{t}= & c+\sum_{j=1}^{P} \beta_{j} F_{t-j}+\sum_{j=1}^{J} \gamma_{j} \ln \lambda_{t-j}+\Omega_{t}^{1 / 2} e_{t} \\
R_{t}= & \operatorname{diag}\left(h_{1 t}, . . h_{N t}\right) \\
\Omega_{t}= & A^{-1} H_{t} A^{-1^{\prime}} \\
H_{t}= & \operatorname{diag}\left(S_{k} \lambda_{t}\right), k=1,2, . . N \\
\ln \lambda_{t}= & \alpha+\beta \ln \lambda_{t-1}+Q^{1 / 2} \eta_{t} \\
\ln h_{i t}= & a_{i}+b_{i} \ln h_{i t-1}+q_{i}^{1 / 2} n_{i t} \\
& \varepsilon_{i t}, e_{t}, \eta_{t}, n_{i t} N(0,1)
\end{aligned}
$$

\section{Estimation}

\subsection{Priors}

\subsubsection{Factor loadings}

The prior on $\tilde{B}_{i}=\left[B_{i} ; \rho_{i}\right]$ is normal and is assumed to be $N\left(B_{i, 0}, V_{B}\right)$ where $B_{i, 0}$ is set equal to the loadings obtained using a principal component estimate of $F_{t}$. The variance $V_{B}$ is assumed to be equal to 1 . The initial estimate of the factors $F_{t}^{P C}$ provides the initial value of the factors $F_{0 \backslash 0}$ with the initial variance set equal to the identity matrix.

\subsubsection{VAR Coefficients}

Following Banbura et al. (2010) we introduce a natural conjugate prior for the VAR parameters $\tilde{b}=\{c, b, \gamma\}$ via dummy observations. In our application, the prior means are chosen as the OLS estimates of the coefficients of an $\mathrm{AR}(1)$ regression estimated for each endogenous variable using a training sample. As is standard for US data, we set the overall prior tightness $\tau=0.1$.

\footnotetext{
*Queen Mary College. Email: h.mumtaz@qmul.ac.uk

$\dagger$ University of Copenhagen. E-mail: laura.sunder-plassmann@econ.ku.dk

$\ddagger$ University of Westminster. Email: A.Theophilopoulou@westminster.ac.uk
} 


\subsubsection{Elements of $S, A$ and the parameters of the common volatility transition equation}

The elements of $S$ have an inverse Gamma prior: $P\left(s_{i}\right)^{\sim} I G\left(S_{0, i}, V_{0}\right)$. The degrees of freedom $V_{0}$ are set equal to 1. The prior scale parameters are set by estimating the following regression: $\bar{\lambda}_{i t}=S_{0, i} \bar{\lambda}_{t}+\varepsilon_{t}$ where $\bar{\lambda}_{t}$ is the first principal component of the stochastic volatilities $\bar{\lambda}_{i t}$ obtained using a univariate stochastic volatility model for the residuals of each equation of the VAR in equation 2 estimated via OLS using the principal components $F_{t}^{P C}$.

The prior for the off-diagonal elements $A$ is $A_{0} \sim N\left(\hat{a}^{o l s}, V\left(\hat{a}^{o l s}\right)\right)$ where $\hat{a}^{\text {ols }}$ are the off-diagonal elements of the inverse of the Cholesky decomposition of $\hat{v}^{\text {ols }}$, with each row scaled by the corresponding element on the diagonal. These OLS estimates are obtained using the initial VAR model described above. $V\left(\hat{a}^{\text {ols }}\right)$ is assumed to be diagonal with the elements set equal to 10 times the absolute value of the corresponding element of $\hat{a}^{\text {ols }}$.

We set a normal prior for the unconditional mean $\mu=\frac{\alpha}{1-\beta}$. This prior is $N\left(\mu_{0}, Z_{0}\right)$ where $\mu_{0}=0$ and $Z_{0}=10$. The prior for $Q$ is $I G\left(Q_{0}, V_{Q 0}\right)$ where $Q_{0}$ is the average of the variances of the transition equations of the initial univariate stochastic volatility estimates and $V_{Q 0}=5$. The prior for $\beta$ is $N\left(F_{0}, L_{0}\right)$ where $F_{0}=0.8$ and $L_{0}=1$.

\subsubsection{Parameters of the idiosyncratic shock volatility transition equation}

We set a normal prior for the unconditional mean $\tilde{\mu}=\frac{a}{1-b}$. This prior is $N\left(\mu_{0}, Z_{0}\right)$ where $\mu_{0}=0$ and $Z_{0}=10$. The prior for $q_{i}$ is $I G\left(q_{0}, V_{q 0}\right)$ where $q_{0}=0.01$ and $V_{q 0}=5$. The prior for $b$ is $N\left(F_{0}, L_{0}\right)$ where $F_{0}=0.8$ and $L_{0}=1$.

\subsection{Gibbs algorithm}

The Gibbs algorithm cycles through the following steps:

1. $G\left(F_{t} \backslash \Xi\right)$ : Given a draw for all other parameters (denoted by $\Xi$ ), the algorithm of Carter and Kohn (2004) is used to sample from the conditional posterior distribution of $F_{t}$. The conditional posterior is: $F_{t} \backslash X_{i t}, \Xi \sim$ $N\left(F_{T \backslash T}, P_{T \backslash T}\right)$ and $F_{t} \backslash F_{t+1}, X_{i t}, \Xi \sim N\left(F_{t \backslash t+1, F_{t+1}}, P_{t \backslash t+1, B_{t+1}}\right)$ where $t=T-1, . .1$. As shown by Carter and Kohn (2004) the simulation proceeds as follows: First, we use the Kalman filter to draw $F_{T \backslash T}$ and $P_{T \backslash T}$ and then proceed backwards in time using $F_{t \mid t+1}=F_{t \mid t}+P_{t \mid t} f^{\prime} P_{t+1 \mid t}^{-1}\left(F_{t+1}-f F_{t \backslash t}-\mu_{t}\right)$ and $P_{t \mid t+1}=P_{t \mid t}-$ $P_{t \mid t} f^{\prime} P_{t+1 \mid t}^{-1} f P_{t \mid t}$. Here $f$ denotes the autoregressive coefficients of the transition equation $2 b$ in companion form, while $\mu_{t}$ denotes the pre-determined regressors in that equation in companion form.

2. $G\left(\tilde{B}_{i} \backslash \Xi\right)$ : Given a draw for the factors and the variance of the idiosyncratic component, a seperate heteroscedastic linear regression model applies to each $X_{i t}$ and the standard formulae for linear regressions apply. In particular, the model for each $i$ is

$$
X_{i t}=\tilde{B}_{i} \tilde{F}_{t}+h_{i t}^{1 / 2} \varepsilon_{i t}
$$

where $\tilde{F}_{t}=\left[F_{t}, \ln h_{i t-1}, \ln h_{i t-2}, \ldots\right]$. The model can be transformed to remove heteroscedasticity by creating $X_{i t}^{*}=\frac{X_{i t}}{\sqrt{h_{i t}}}, \tilde{F}_{t}^{*}=\frac{\tilde{F}_{t}}{\sqrt{h_{i t}}}$ The conditional posterior is $N\left(B_{i}^{*}, \Lambda_{B}\right)$ where

$$
\begin{aligned}
& B_{i}^{*}=\left(V_{B}^{-1}+\tilde{F}_{t}^{* \prime} \tilde{F}_{t}^{*}\right)^{-1}\left(V_{B}^{-1} B_{i, 0}+\tilde{F}_{t}^{* \prime} X_{i t}^{*}\right) \\
& \Lambda_{B}=\left(V_{B}^{-1}+\tilde{F}_{t}^{* \prime} \tilde{F}_{t}^{*}\right)^{-1}
\end{aligned}
$$

3. $G\left(h_{i t} \backslash \Xi\right)$ : Given a draw for the factors, the parameters of the transition equation 7 and the factor loadings $\tilde{B}_{i}$, a univariate stochastic volatility in mean model applies for each $i$ :

$$
\begin{aligned}
X_{i t} & =B_{i} F_{t}+\sum_{k=1}^{K} \rho_{i, l} \ln h_{i t-l}+h_{i t}^{1 / 2} \varepsilon_{i t} \\
\ln h_{i t} & =a_{i}+b_{i} \ln h_{i t-1}+q_{i}^{1 / 2} n_{i t}
\end{aligned}
$$

The algorithm of Jacquier et al. (1994) (described below) is used to draw $h_{i t}$. 
4. $G(\tilde{b} \backslash \Xi)$. Given a draw of $\lambda_{t}$, the left and the right hand side variables of the VAR: $y_{t}=F_{t}$ and $x_{t}=$ $\left[c, F_{t-1}, F_{t-2}, . . F_{t-j}, \lambda_{t}, \lambda_{t-1}, . . \lambda_{t-j}\right]$ can be transformed to remove the heteroscedasticity in the following manner

$$
\tilde{y}_{t}=\frac{y_{t}}{\lambda_{t}^{1 / 2}}, \tilde{x}_{t}=\frac{x_{t}}{\lambda_{t}^{1 / 2}}
$$

Then the conditional posterior distribution for the VAR coefficients is standard and given by

$$
N\left(\tilde{b}^{*}, \bar{\Omega} \otimes\left(X^{* \prime} X^{*}\right)^{-1}\right)
$$

where $\tilde{b}^{*}=\left(X^{* \prime} X^{*}\right)^{-1}\left(X^{* \prime} Y^{*}\right), \bar{\Omega}=A^{-1} \operatorname{diag}(S) A^{-1 \prime}$ and $Y^{*}$ and $X^{*}$ denote the transformed data appended with the dummy observations.

5. $G(A \backslash \Xi)$. Given a draw for the VAR parameters the model can be written as $A^{\prime}\left(v_{t}\right)=\tilde{e}_{t}$ where $v_{t}=F_{t}-$ $\left(c+\sum_{j=1}^{P} \beta_{j} F_{t-j}+\sum_{j=1}^{J} \gamma_{j} \ln \lambda_{t-j}\right)$ and $\operatorname{VAR}\left(\tilde{e}_{t}\right)=H_{t}$. This is a system of linear equations with a known form of heteroscedasticity. The conditional distributions for a linear regression apply to each equation of this system after a simple GLS transformation to make the errors homoscedastic. The $j$ th equation of this system is given as $v_{j t}=-\alpha v_{-j t}+\tilde{e}_{j t}$ where the subscript $j$ denotes the $j t h$ column while $-j$ denotes columns 1 to $j-1$. Note that the variance of $\tilde{e}_{j t}$ is time-varying and given by $\lambda_{t} S_{j}$. A GLS transformation involves dividing both sides of the equation by $\sqrt{\lambda_{t} S_{j}}$ to produce $v_{j t}^{*}=-\alpha v_{-j t}^{*}+\tilde{e}_{j t}^{*}$ where ${ }^{*}$ denotes the transformed variables and $\operatorname{var}\left(\tilde{e}_{j t}^{*}\right)=1$. The conditional posterior for $\alpha$ is normal with mean and variance given by $M^{*}$ and $V^{*}$ :

$$
\begin{aligned}
M^{*} & =\left(V\left(\hat{a}^{o l s}\right)^{-1}+v_{-j t}^{* \prime} v_{-j t}^{*}\right)^{-1}\left(V\left(\hat{a}^{o l s}\right)^{-1} \hat{a}^{o l s}+v_{-j t}^{* \prime} v_{j t}^{*}\right) \\
V^{*} & =\left(V\left(\hat{a}^{o l s}\right)^{-1}+v_{-j t}^{* \prime} v_{-j t}^{*}\right)^{-1}
\end{aligned}
$$

6. $G(S \backslash \Xi)$. Given a draw for the VAR parameters $A^{\prime}\left(v_{t}\right)=\tilde{e}_{t}$. The jth equation of this system is given by $v_{j t}=-\alpha v_{-j t}+\tilde{e}_{j t}$ where the variance of $e_{j t}$ is time-varying and given by $\lambda_{t} S_{j}$. Given a draw for $\lambda_{t}$ this equation can be re-written as $\bar{v}_{j t}=-\alpha \bar{v}_{-j t}+\bar{e}_{j t}$ where $\bar{v}_{j t}=\frac{v_{j t}}{\lambda_{t}^{1 / 2}}$ and the variance of $\bar{e}_{j t}$ is $S_{j}$. The conditional posterior is for this variance is inverse Gamma with scale parameter $\bar{e}_{j t}^{\prime} \bar{e}_{j t}+S_{0, j}$ and degrees of freedom $V_{0}+T$.

7. Elements of $\lambda_{t}$. Conditional on the VAR coefficients, and the parameters of the volatility transition equation, the model has a multivariate non-linear state-space representation. Carlin et al. (1992) show that the conditional distribution of the state variables in a general state-space model can be written as the product of three terms:

$$
\tilde{h}_{t} \backslash Z_{t}, \Xi \propto f\left(\tilde{h}_{t} \backslash \tilde{h}_{t-1}\right) \times f\left(\tilde{h}_{t+1} \backslash \tilde{h}_{t}\right) \times f\left(Z_{t} \backslash \tilde{h}_{t}, \Xi\right)
$$

where $\Xi$ denotes all other parameters, $Z_{t}$ denotes the endogenous variables in equation 2 and $\tilde{h}_{t}=\ln \lambda_{t}$. In the context of stochastic volatility models, Jacquier et al. (1994) show that this density is a product of log normal densities for $\lambda_{t}$ and $\lambda_{t+1}$ and a normal density for $Z_{t}$. Carlin et al. (1992) derive the general form of the mean and variance of the underlying normal density for $f\left(\tilde{h}_{t} \backslash \tilde{h}_{t-1}, \tilde{h}_{t+1}, \Xi\right) \propto f\left(\tilde{h}_{t} \backslash \tilde{h}_{t-1}\right) \times f\left(\tilde{h}_{t+1} \backslash \tilde{h}_{t}\right)$ and show that this is given as

$$
f\left(\tilde{h}_{t} \backslash \tilde{h}_{t-1}, \tilde{h}_{t+1}, \Xi\right) \sim N\left(B_{2 t} b_{2 t}, B_{2 t}\right)
$$

where $B_{2 t}^{-1}=Q^{-1}+F^{\prime} Q^{-1} F$ and $b_{2 t}=\tilde{h}_{t-1} F^{\prime} Q^{-1}+\tilde{h}_{t+1} Q^{-1} F$. Note that due to the non-linearity of the observation equation of the model an analytical expression for the complete conditional $\tilde{h}_{t} \backslash Z_{t}, \Xi$ is unavailable and a metropolis step is required. Following Jacquier et al. (1994) we draw from 9 using a date-by-date independence metropolis step using the density in 10 as the candidate generating density. This choice implies that the acceptance probability is given by the ratio of the conditional likelihood $f\left(Z_{t} \backslash \tilde{h}_{t}, \Xi\right)$ at the old and the new draw. To implement the algorithm we begin with an initial estimate of $\tilde{h}=\ln \bar{\lambda}_{t}$ We set the matrix $\tilde{h}^{\text {old }}$ equal to the initial volatility estimate. Then at each date the following two steps are implemented:

(a) Draw a candidate for the volatility $\tilde{h}_{t}^{\text {new }}$ using the density 9 where $b_{2 t}=\tilde{h}_{t-1}^{\text {new }} F^{\prime} Q^{-1}+\tilde{h}_{t+1}^{\text {old }} Q^{-1} F$ and $B_{2 t}^{-1}=Q^{-1}+F^{\prime} Q^{-1} F$ 
(b) Update $\tilde{h}_{t}^{\text {old }}=\tilde{h}_{t}^{\text {new }}$ with acceptance probability $\frac{f\left(Z_{t} \backslash \tilde{h}_{t}^{\text {new }}, \Xi\right)}{f\left(Z_{t} \backslash \tilde{h}_{t}^{\text {old }}, \Xi\right)}$ where $f\left(Z_{t} \backslash \tilde{h}_{t}, \Xi\right)$ is the likelihood of the VAR for observation $t$ and defined as $\left|\Omega_{t}\right|^{-0.5}-0.5 \exp \left(\tilde{e}_{t} \Omega_{t}^{-1} \tilde{e}_{t}^{\prime}\right)$ where

$$
\tilde{e}_{t}=F_{t}-\left(c+\sum_{j=1}^{P} \beta_{j} F_{t-j}+\sum_{j=1}^{J} \gamma_{j} \ln \lambda_{t-j}+\Omega_{t}^{1 / 2} e_{t}\right) \text { and } \Omega_{t}=A^{-1}\left(\exp \left(\tilde{h}_{t}\right) S\right) A^{-1^{\prime}}
$$

Repeating these steps for the entire time series delivers a draw of the stochastic volatilties 1

7. $G(\alpha, \beta, Q \backslash \Xi)$.We re-write the transition equation in deviations from the mean

$$
\tilde{h}_{t}-\mu=\beta\left(\tilde{h}_{t-1}-\mu\right)+\eta_{t}
$$

where the elements of the mean vector $\mu$ are defined as $\frac{\alpha}{1-\beta}$. Conditional on a draw for $\tilde{h}_{t}$ and $\mu$ the transition equation 11 is a simply a linear regression and the standard normal and inverse Gamma conditional posteriors apply. Consider $\tilde{h}_{t}^{*}=\beta \tilde{h}_{t-1}^{*}+\eta_{t}, V A R\left(\eta_{t}\right)=Q$ and $\tilde{h}_{t}^{*}=\tilde{h}_{t}-\mu, \tilde{h}_{t-1}^{*}=\tilde{h}_{t-1}-\mu$. The conditional posterior of $\beta$ is $N\left(\theta^{*}, L^{*}\right)$ where

$$
\begin{aligned}
\theta^{*} & =\left(L_{0}^{-1}+\frac{1}{Q} \tilde{h}_{t-1}^{* \prime} \tilde{h}_{t-1}^{*}\right)^{-1}\left(L_{0}^{-1} F_{0}+\frac{1}{Q} \tilde{h}_{t-1}^{* \prime} \tilde{h}_{t}^{*}\right) \\
L^{*} & =\left(L_{0}^{-1}+\frac{1}{Q} \tilde{h}_{t-1}^{* \prime} \tilde{h}_{t-1}^{*}\right)^{-1}
\end{aligned}
$$

The conditional posterior of $Q$ is inverse Gamma with scale parameter $\eta_{t}^{\prime} \eta_{t}+Q_{0}$ and degrees of freedom $T+V_{Q 0}$.

Given a draw for $\beta$, equation 11 can be expressed as $\bar{\Delta} \tilde{h}_{t}=C \mu+\eta_{t}$ where $\bar{\Delta} \tilde{h}_{t}=\tilde{h}_{t}-\beta \tilde{h}_{t-1}$ and $C=1-\beta$. The conditional posterior of $\mu$ is $N\left(\mu^{*}, Z^{*}\right)$ where

$$
\begin{aligned}
\mu^{*} & =\left(Z_{0}^{-1}+\frac{1}{Q} C^{\prime} C\right)^{-1}\left(Z_{0}^{-1} \mu_{0}+\frac{1}{Q} C^{\prime} \bar{\Delta} \tilde{h}_{t}\right) \\
Z^{*} & =\left(Z_{0}^{-1}+\frac{1}{Q} C^{\prime} C\right)^{-1}
\end{aligned}
$$

Note that $\alpha$ can be recovered as $\mu(1-\beta)$

8. $G\left(a_{i}, b_{i}, q_{i} \backslash \Xi\right)$. Given a draw for $h_{i t}$, the conditional posterior distributions for the parameters of the transition equations 7 are as described in step 7 .

\subsection{A Monte-Carlo experiment}

In order to examine the performance of this algorithm, we consider a small Monte-Carlo experiment

\subsubsection{Data Generating Process}

We generate data from the following FAVAR model with 2 factors:

$$
X_{i t}=B_{i} F_{t}+R^{1 / 2} \varepsilon_{i t}
$$

where $R=0.1$, the factor loadings $B_{i}$ are drawn from $N(0,0.1)$ and $i=1,2, \ldots 100$.

The dynamics of the factors are defined as

$$
\left(\begin{array}{l}
F_{1 t} \\
F_{2 t}
\end{array}\right)=\left(\begin{array}{cc}
0.7 & 0.1 \\
-0.1 & 0.5
\end{array}\right)\left(\begin{array}{c}
F_{1 t-1} \\
F_{2 t-1}
\end{array}\right)+\left(\begin{array}{c}
-0.5 \\
0.5
\end{array}\right) \ln \lambda_{t}+\left(\begin{array}{c}
v_{1 t} \\
v_{2 t}
\end{array}\right), \operatorname{var}\left(\begin{array}{l}
v_{1 t} \\
v_{2 t}
\end{array}\right)=\Omega_{t}
$$

\footnotetext{
${ }^{1}$ In order to take endpoints into account, the algorithm is modified slightly for the initial condition and the last observation. Details of these changes can be found in Jacquier et al. (1994).
} 
The variance process is defined as

$$
\begin{aligned}
\Omega_{t} & =A^{-1}\left(S \lambda_{t}\right) A^{-1^{\prime}} \\
A & =\left(\begin{array}{cc}
1 & 0 \\
-1 & 1
\end{array}\right) \\
S & =\left(\begin{array}{cc}
1 & 0 \\
0 & 2
\end{array}\right) \\
\ln \lambda_{t} & =-0.1+0.75 \ln \lambda_{t-1}+(0.5)^{\frac{1}{2}} v_{t}
\end{aligned}
$$

We generate 500 observations for $X_{i t}$ and drop the first 100 observations to reduce the influenceof initial conditions. The experiment is repeated 500 times. At each iteration, the FAVAR model is estimated using the MCMC algorithm described above using 5000 iterations with a burn-in of 4000 observations. The retained draws are used to calculate the impulse response of $X_{i t}$ to a 1 standard deviation shock to $\ln \lambda_{t}$ for a horizon of 20 periods. In the figures below we report the difference between the cumulated response at various horizons estimated via the MCMC algorithm and the response using the true parameter values for each of the $\mathrm{N} X_{i t}$. The figure below shows that, on average, the difference in the estimated responses and the true responses is zero across the panel and across the different horizons considered. This provides evidence that the MCMC algorithm performs well.
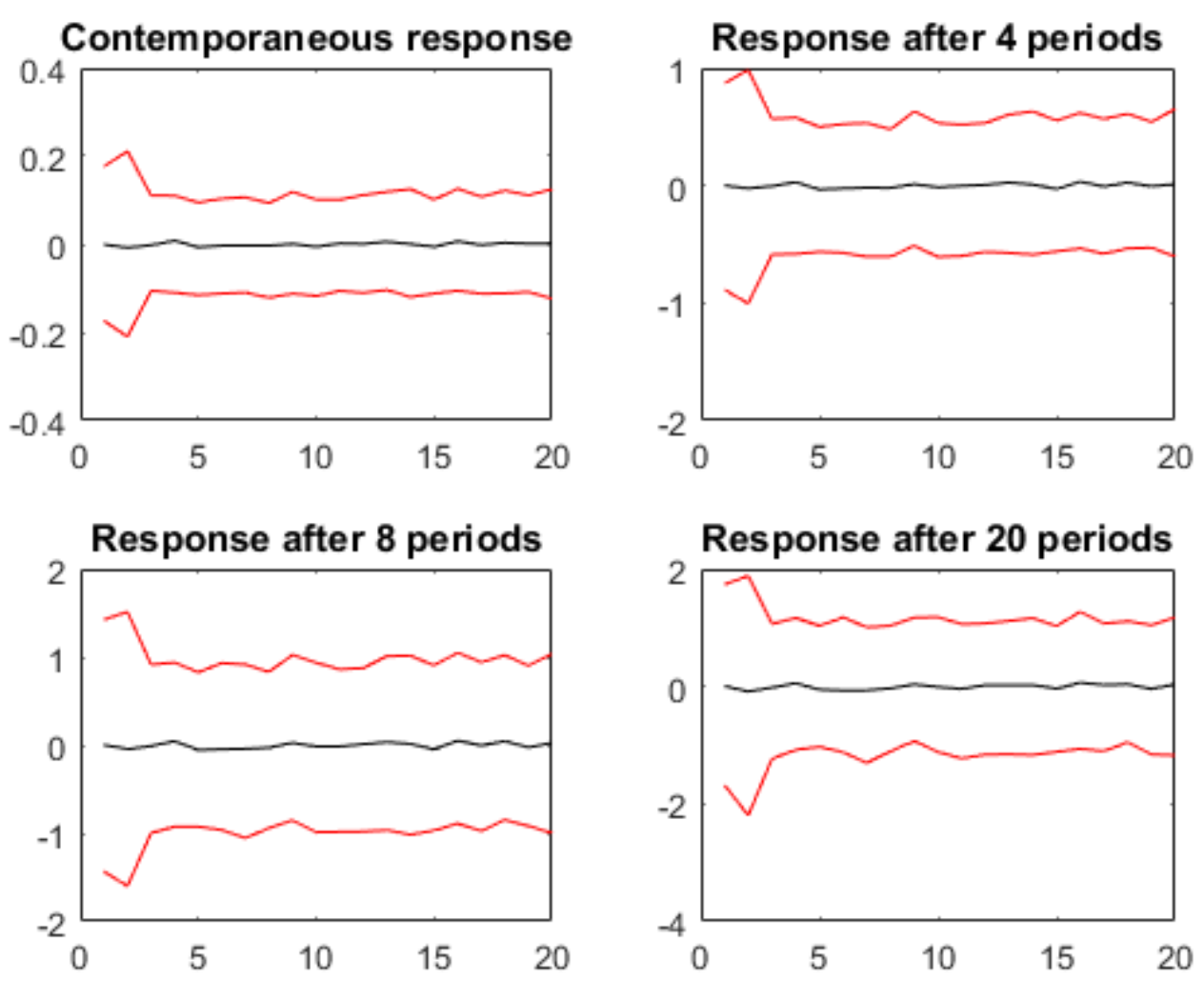

Figure 1: Monte-Carlo experiment

\section{Sensitivity Analysis}

\subsection{Number of factors}

We re-estimate the model and set the number of factors to 5 . Figure 2 shows the correlation between the long run cumulated response of state-level income obtained from the five-factor model and the benchmark model 2 The scatter plot in the figure shows that the pattern of state-level responses in this model is very similar to the benchmark case- in fact the cross-sectional correlation between the two sets of responses at this horizon is 0.8 .

\footnotetext{
${ }^{2}$ The long run response is proxied by the cumulated response at the 40 quarter horizon
} 


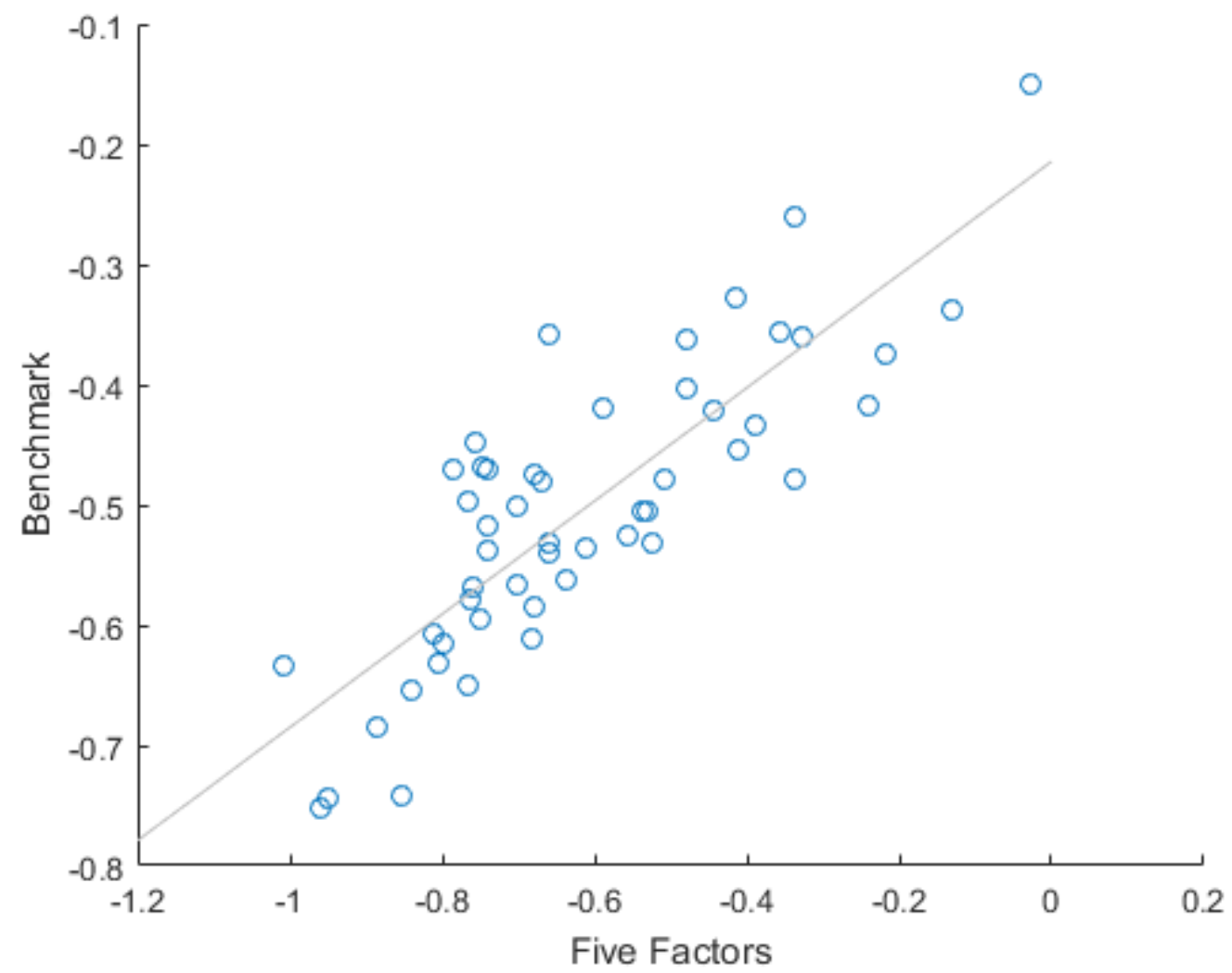

Figure 2: using five factors

\subsection{Using Employment}

We re-estimate the benchmark model replacing state-level real income with the growth of non-farm employment in each state. Figure 3 plots the long run cumulated responses of state-level real income from the benchmark model against the long run cumulated response of state-level employment. The figure shows that there is a high correlation (of about $70 \%$ ) between the benchmark estimates and the employment responses. 


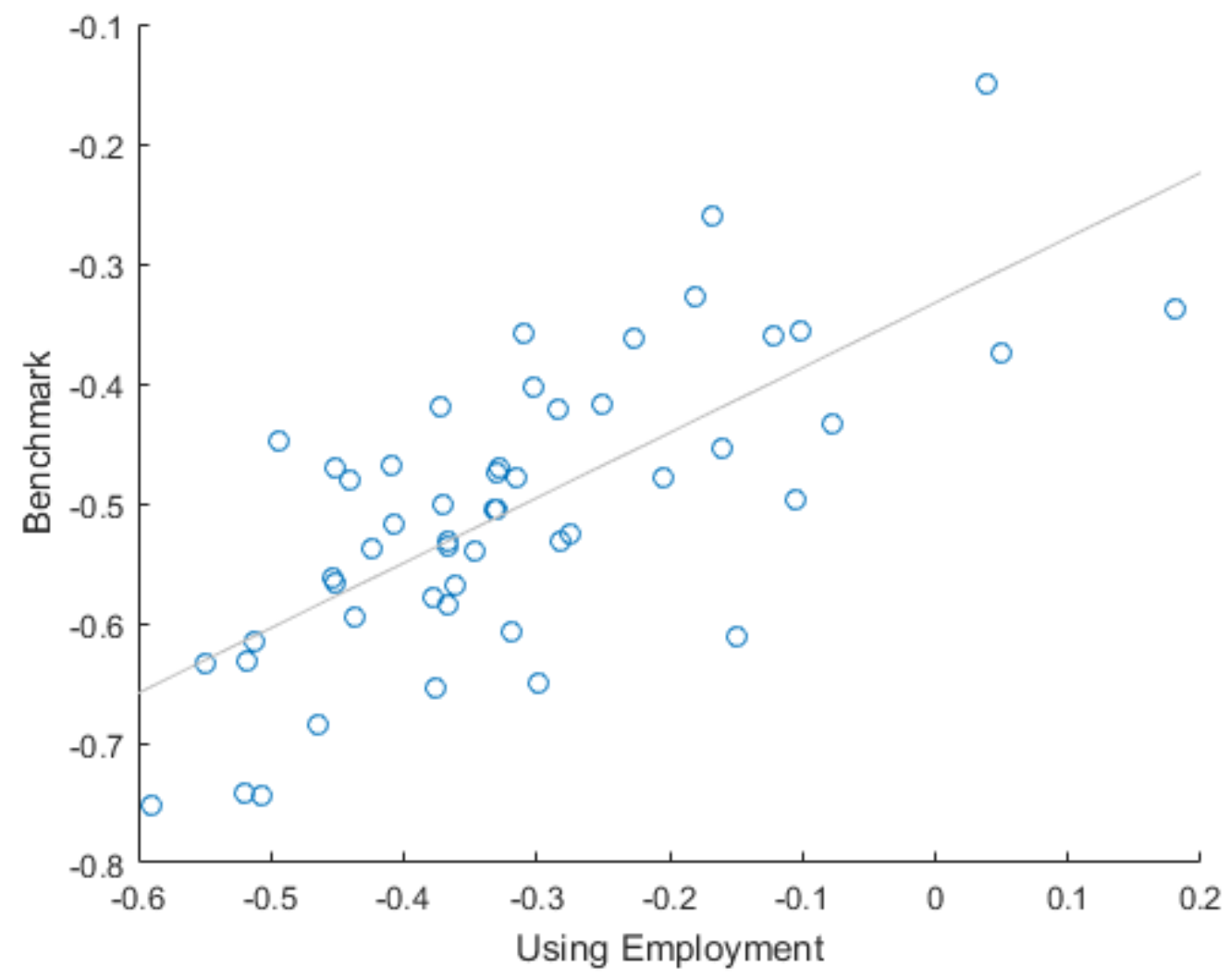

Figure 3: using Employment

\subsection{Using a simple FAVAR model}

We consider an alternative (and simpler) FAVAR model:

$$
\begin{aligned}
X_{i t} & =B_{i} \tilde{F}_{t}+v_{i t} \\
Z_{t} & =c+\sum_{j=1}^{P} \beta_{j} Z_{t-j}+e_{t} \\
\operatorname{var}\left(e_{t}\right) & =\Omega=A_{0} A_{0}^{\prime}
\end{aligned}
$$

where $\tilde{F}_{t}$ represents a set of common factors $\left(X_{i t}\right.$ is the panel of data) and $Z_{t}=\left[\tilde{F}_{t}, \ln \varpi_{t}\right]$ with $\varpi_{t}$ the uncertainty measure taken from Jurado et al. (2015). This is a standard FAVAR where $\ln \varpi_{t}$ is considered an observed factor. One can then calculate the response of state-level income included in $X_{i t}$ to shocks to the equation for $\ln \varpi_{t}$ in the VAR model $Z_{t}=c+\sum_{j=1}^{P} \beta_{j} Z_{t-j}+e_{t}$. We assume that $A_{0}$ is the Cholesky decomposition of $\Omega$ with the ordering $\left[\tilde{F}_{t}, \ln \varpi_{t}\right]$ that is consistent with our benchmark model. We use three factors as in the benchmark model, setting the lag length to 4 . 


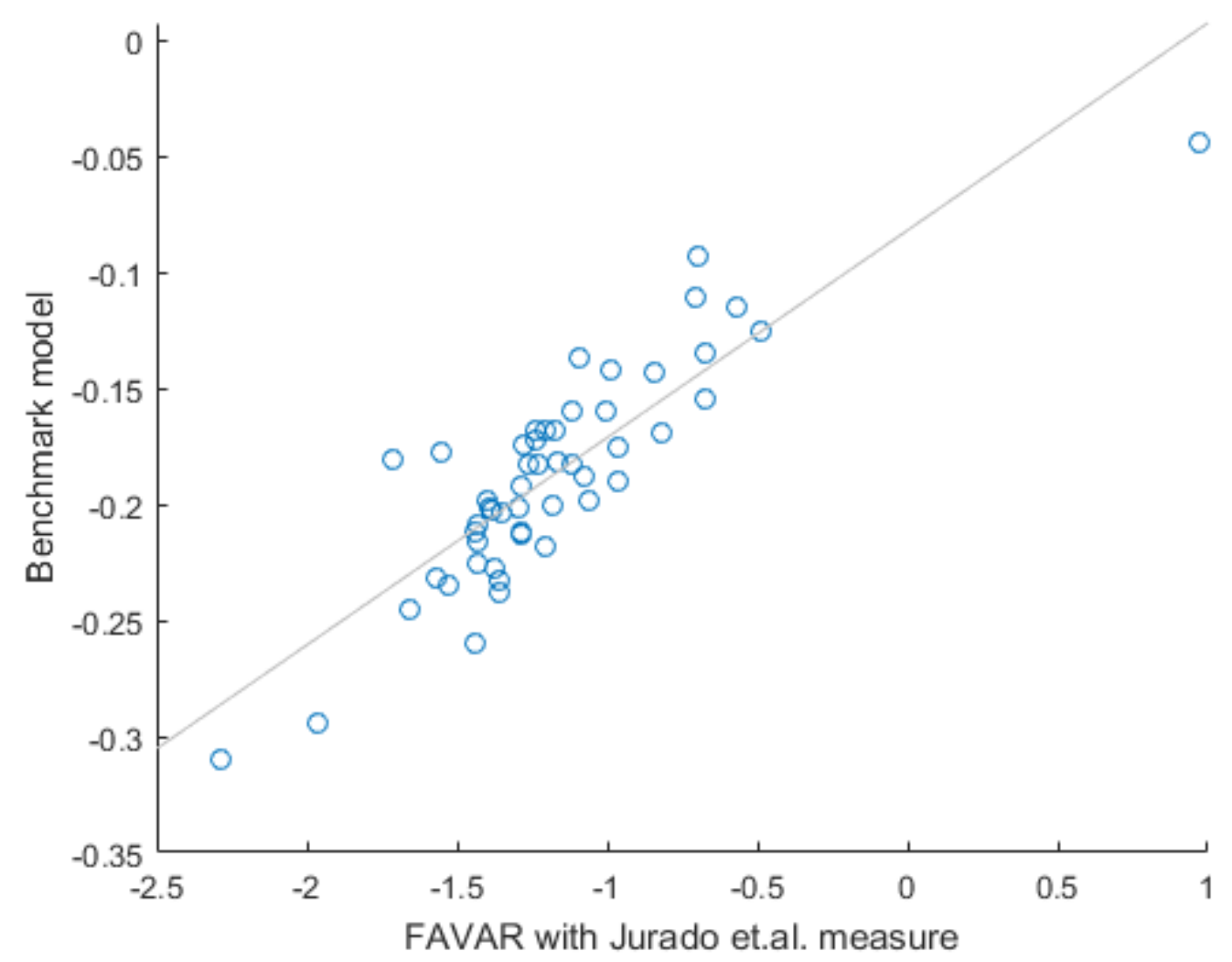

Figure 4: using a simple FAVAR

In Figure 4 we compare the cumulated response of the state-level income to a one standard deviation uncertainty shock (at the 2 year horizon) obtained from this FAVAR (using the Jurado et al. (2015) measure of uncertainty) with the same response obtained from the benchmark model in the paper. The x-axis shows the 51 state-level responses from the FAVAR model (using the Jurado et al. (2015) measure of uncertainty) while y-axis shows the 51 state-level responses from the benchmark model. It is clear from the scatter plot that the FAVAR delivers a pattern of responses very similar to the Benchmark model with a correlation coefficient of 0.86 between the two cross-sections. This is re-assuring as it provides further support for the results in the paper. Notice, however, that while the cross-state pattern delivered by the models is similar, there is a large difference in the scale of the responses. The simple FAVAR delivers responses with a larger magnitude for all states ${ }^{3}$ Recall that a key difference between this FAVAR and our proposed model is the fact that the observation equation of this model $X_{i t}=B_{i} \tilde{F}_{t}+v_{i t}$ does not account for the impact of idiosyncratic/State-specific uncertainty shocks which are proxied by the term $\sum_{k=1}^{K} \rho_{k, i} \ln h_{i t-k}$ in the observation equation of the proposed model. This omission may explain why the simpler model indicates that aggregate uncertainty shocks have quite large effects on state-level income, a result that may simply reflect a statistical bias.

\subsection{Robustness of the cross section results}

Table (1) documents further evidence on the industry mix effects on the state response to uncertainty shocks, after controling for our baseline effects. Column 1 is the baseline specification. Column 2 shows that oil and mining have very similar effects. Columns 3 through 5 show that agriculture, financial services and housing sectors are not important once we have controlled for our baseline mix. Column 6 shows that construction is only significant once we control for the effects of budget deficts and intergovernment transfers.

Table (2) explores the roles of regressors used in the literature on explaining state-level heterogeneity. Column 1 is again the baseline specification. We next investigate where the prevalence of small banks plays an important role. Columns 2 and 3 include as regressors the fraction of loans extended by small banks where small is defined as at

\footnotetext{
${ }^{3}$ This result does not depend on the scale of the shock. That is, if the shock is scaled to be exactly the same in the two models, the same results are obtained.
} 


\begin{tabular}{|c|c|c|c|c|c|c|}
\hline & (1) & (2) & (3) & (4) & (5) & (6) \\
\hline Manufacturing & $\begin{array}{c}-0.379^{* * *} \\
(0.080)\end{array}$ & $\begin{array}{c}-0.381^{* * *} \\
(0.075)\end{array}$ & $\begin{array}{c}-0.404^{* * *} \\
(0.083)\end{array}$ & $\begin{array}{c}-0.382^{* * *} \\
(0.095)\end{array}$ & $\begin{array}{c}-0.386^{* * *} \\
(0.091)\end{array}$ & $\begin{array}{c}-0.260^{* * * *} \\
(0.080)\end{array}$ \\
\hline Mining & $\begin{array}{c}0.475^{* * *} \\
(0.099)\end{array}$ & & $\begin{array}{c}0.441^{* * *} \\
(0.113)\end{array}$ & $\begin{array}{c}0.470^{* * *} \\
(0.117)\end{array}$ & $\begin{array}{c}0.461^{* * *} \\
(0.120)\end{array}$ & $\begin{array}{c}0.426^{* * *} \\
(0.126)\end{array}$ \\
\hline Oil & & $\begin{array}{c}0.493^{* * *} \\
(0.099)\end{array}$ & & & & \\
\hline Home vacancy rate & $\begin{array}{c}-2.742^{* * *} \\
(0.866)\end{array}$ & $\begin{array}{c}-2.834^{* * *} \\
(0.820)\end{array}$ & $\begin{array}{c}-2.928^{* * *} \\
(0.918)\end{array}$ & $\begin{array}{c}-2.750^{* * *} \\
(0.882)\end{array}$ & $\begin{array}{c}-2.769^{* * *} \\
(0.902)\end{array}$ & $\begin{array}{r}-3.833^{* * *} \\
(0.881)\end{array}$ \\
\hline Right to work & $\begin{array}{c}-0.028^{* * *} \\
(0.009)\end{array}$ & $\begin{array}{c}-0.025^{* *} \\
(0.010)\end{array}$ & $\begin{array}{l}-0.024^{*} \\
(0.013)\end{array}$ & $\begin{array}{c}-0.029^{* *} \\
(0.012)\end{array}$ & $\begin{array}{c}-0.030^{* *} \\
(0.012)\end{array}$ & $\begin{array}{r}-0.027^{* * *} \\
(0.009)\end{array}$ \\
\hline Small firms $(<250)$ & $\begin{array}{c}-0.443^{* * *} \\
(0.136)\end{array}$ & $\begin{array}{c}-0.374^{* *} \\
(0.139)\end{array}$ & $\begin{array}{c}-0.395^{* *} \\
(0.179)\end{array}$ & $\begin{array}{c}-0.448^{* * *} \\
(0.161)\end{array}$ & $\begin{array}{c}-0.444^{* * *} \\
(0.141)\end{array}$ & $\begin{array}{c}-0.254^{*} \\
(0.142)\end{array}$ \\
\hline Budget deficit & $\begin{array}{c}-0.132^{* *} \\
(0.063)\end{array}$ & $\begin{array}{c}-0.090^{* *} \\
(0.044)\end{array}$ & $\begin{array}{c}-0.127^{*} \\
(0.063)\end{array}$ & $\begin{array}{c}-0.131^{* *} \\
(0.064)\end{array}$ & $\begin{array}{c}-0.131^{* *} \\
(0.063)\end{array}$ & \\
\hline Intergov't transfers & $\begin{array}{l}0.193^{* *} \\
(0.073)\end{array}$ & $\begin{array}{l}0.198^{* *} \\
(0.076)\end{array}$ & $\begin{array}{l}0.193^{* *} \\
(0.074)\end{array}$ & $\begin{array}{l}0.193^{* *} \\
(0.072)\end{array}$ & $\begin{array}{c}0.190^{* *} \\
(0.071)\end{array}$ & \\
\hline Construction & $\begin{array}{c}-2.421^{* * *} \\
(0.701)\end{array}$ & $\begin{array}{c}-2.193^{* * *} \\
(0.657)\end{array}$ & $\begin{array}{c}-2.459^{* * *} \\
(0.710)\end{array}$ & $\begin{array}{c}-2.438^{* * *} \\
(0.743)\end{array}$ & $\begin{array}{c}-2.394^{* * *} \\
(0.710)\end{array}$ & $\begin{array}{l}-1.178 \\
(0.730)\end{array}$ \\
\hline Agriculture & & & $\begin{array}{l}-0.147 \\
(0.215)\end{array}$ & & & \\
\hline Financial services & & & & $\begin{array}{l}-0.015 \\
(0.199)\end{array}$ & & \\
\hline Real estate & & & & & $\begin{array}{c}-0.063 \\
(0.268)\end{array}$ & \\
\hline Observations & 50 & 50 & 50 & 50 & 50 & 51 \\
\hline Adjusted $R^{2}$ & 0.719 & 0.675 & 0.716 & 0.712 & 0.712 & 0.630 \\
\hline
\end{tabular}

Table 1: Industry Mix 
or below the 90th and 70th, respectively, percentile of the national asset distribution of financial institutions. Both have negative, but not significant effects. Column 4 includes as a regressor the share of employment accounted for by small establishments, where small is defined as establishments with less than 10 employees rather than 250 as in the baseline. The effect is significant but less so that for the baseline measure. Finally column 6 is the specification used in Carlino, which does not include our baseline controls, but only the manufacturing share, small banks and small firms measures. Neither the bank nor the firm measure are significant.

Table (3) further investigates the role of various aspects of state government finances in driving the uncertainty shock responses. Comparing to the baseline specification in column 1, columns 2 and 3 show that the size of the public sector in state GDP matters conditionally on budget deficits and intergovernmental transfers. It ameliorates the state response to an uncertainty shock. Column 3 through 6 show that expenditures on unemployment insurance, welfare programs and government debt have no significant effects on state-level uncertainty shock responses.

Table (4) shows in column 2 that an alternative measure of labor market flexibility, union membership, mirrors the effect of right to work legislation but is not significant. Column 3 and 4 show that business creation as measured by the net entry rate of establishments is not significant once controlling for the share of construction in GDP - the two measures are highly correlated across states.

Table (5) shows that alternative measures of housing market conditions have comparable effects as our baseline measure of home vacancy rate. Specifically, home ownership rates, rental vacancy rates or their volatility are significant and negative - they exacerbate the state IRF to uncertainty shocks - with the only exception being the home ownership rate which turns out to be insignificant.

Table (6) shows that our results are robust to considering the uncertainty shock response at different horizons from 1 quarter to 4 years. At very short horizons of 1 quarter, the confidence intervals around the responses are wider and some effects insignificant although qualitatively comparable to the longer horizons. For all but the very shortest horizon, the results are both qualitatively and quantitatively robust.

Table (7) compares the benchmark regression estimates (first column) with those obtained when the two year cumulated IRFs from the simple FAVAR are used (second column). It is clear that the sign of the coefficients is the same across specifications. The magnitude of the coefficients differs as the magnitude of the responses obtained from the simple FAVAR is larger.

\section{Data}

\subsection{Data for FAVAR}

The FAVAR model includes 91 Macroeconomic and Financial time-series and real personal income for 51 states. The data for total personal income for each state is obtained from FRED. These series are divided by CPI and then transformed by taking the log difference and multiplying by 100. The table below lists the 91 Macroeconomic and Financial time-series. In terms of the data sources GFD refers to Global Financial Database, FRED is the Federal Reserve Bank of St Louis database. D denotes the log difference transformation (times 100), while N denotes no transformation. 


\begin{tabular}{|c|c|c|c|c|c|}
\hline & (1) & $(2)$ & (3) & (4) & (5) \\
\hline Manufacturing & $\begin{array}{c}-0.379^{* * *} \\
(0.080)\end{array}$ & $\begin{array}{c}-0.379^{* * *} \\
(0.082)\end{array}$ & $\begin{array}{c}-0.385^{* * *} \\
(0.082)\end{array}$ & $\begin{array}{c}-0.379^{* * *} \\
(0.091)\end{array}$ & $\begin{array}{c}-0.477^{* * *} \\
(0.106)\end{array}$ \\
\hline Mining & $\begin{array}{c}0.475^{* * *} \\
(0.099)\end{array}$ & $\begin{array}{c}0.488^{* * *} \\
(0.099)\end{array}$ & $\begin{array}{c}0.490^{* * *} \\
(0.099)\end{array}$ & $\begin{array}{c}0.447^{* * *} \\
(0.104)\end{array}$ & \\
\hline Home vacancy rate & $\begin{array}{c}-2.742^{* * *} \\
(0.866)\end{array}$ & $\begin{array}{c}-2.734^{* * *} \\
(0.874)\end{array}$ & $\begin{array}{c}-2.709^{* * *} \\
(0.878)\end{array}$ & $\begin{array}{c}-2.483^{* *} \\
(0.920)\end{array}$ & \\
\hline Right to work & $\begin{array}{c}-0.028^{* * *} \\
(0.009)\end{array}$ & $\begin{array}{c}-0.027^{* * *} \\
(0.010)\end{array}$ & $\begin{array}{c}-0.027^{* * *} \\
(0.009)\end{array}$ & $\begin{array}{c}-0.025^{* *} \\
(0.010)\end{array}$ & \\
\hline Small firms $(<250)$ & $\begin{array}{c}-0.443^{* * *} \\
(0.136)\end{array}$ & $\begin{array}{c}-0.410^{* *} \\
(0.160)\end{array}$ & $\begin{array}{c}-0.416^{* * *} \\
(0.152)\end{array}$ & & $\begin{array}{c}0.249 \\
(0.227)\end{array}$ \\
\hline Budget deficit & $\begin{array}{c}-0.132^{* *} \\
(0.063)\end{array}$ & $\begin{array}{c}-0.138^{* *} \\
(0.061)\end{array}$ & $\begin{array}{c}-0.137^{* *} \\
(0.061)\end{array}$ & $\begin{array}{c}-0.118^{*} \\
(0.062)\end{array}$ & \\
\hline Intergov't transfers & $\begin{array}{l}0.193^{* *} \\
(0.073)\end{array}$ & $\begin{array}{l}0.184^{* *} \\
(0.077)\end{array}$ & $\begin{array}{l}0.183^{* *} \\
(0.077)\end{array}$ & $\begin{array}{c}0.200^{* * *} \\
(0.068)\end{array}$ & \\
\hline Construction & $\begin{array}{c}-2.421^{* * *} \\
(0.701)\end{array}$ & $\begin{array}{c}-2.367^{* * *} \\
(0.733)\end{array}$ & $\begin{array}{c}-2.472^{* * *} \\
(0.699)\end{array}$ & $\begin{array}{c}-1.768^{* *} \\
(0.857)\end{array}$ & \\
\hline Small banks $\left(\leq 90^{t h}\right.$ pctile $)$ & & $\begin{array}{l}-0.011 \\
(0.022)\end{array}$ & & & $\begin{array}{l}-0.018 \\
(0.022)\end{array}$ \\
\hline Small banks $\left(\leq 70^{t h}\right.$ pctile $)$ & & & $\begin{array}{c}-0.021 \\
(0.037)\end{array}$ & & \\
\hline Small firms $(<10)$ & & & & $\begin{array}{c}-0.404^{*} \\
(0.208) \\
\end{array}$ & \\
\hline Observations & 50 & 50 & 50 & 50 & 51 \\
\hline Adjusted $R^{2}$ & 0.719 & 0.714 & 0.714 & 0.682 & 0.312 \\
\hline
\end{tabular}

Table 2: Financial Frictions 


\begin{tabular}{|c|c|c|c|c|c|c|}
\hline & (1) & (2) & (3) & (4) & (5) & (6) \\
\hline Manufacturing & $\begin{array}{c}-0.379^{* * *} \\
(0.080)\end{array}$ & $\begin{array}{c}-0.313^{* * *} \\
(0.078)\end{array}$ & $\begin{array}{l}-0.201^{*} \\
(0.100)\end{array}$ & $\begin{array}{c}-0.388^{* * *} \\
(0.084)\end{array}$ & $\begin{array}{c}-0.387^{* * *} \\
(0.092)\end{array}$ & $\begin{array}{c}-0.379^{* * *} \\
(0.079)\end{array}$ \\
\hline Mining & $\begin{array}{c}0.475^{* * *} \\
(0.099)\end{array}$ & $\begin{array}{c}0.520^{* * *} \\
(0.088)\end{array}$ & $\begin{array}{c}0.434^{* * *} \\
(0.119)\end{array}$ & $\begin{array}{c}0.468^{* * *} \\
(0.100)\end{array}$ & $\begin{array}{c}0.480^{* * *} \\
(0.098)\end{array}$ & $\begin{array}{c}0.468^{* * *} \\
(0.104)\end{array}$ \\
\hline Home vacancy rate & $\begin{array}{c}-2.742^{* * *} \\
(0.866)\end{array}$ & $\begin{array}{c}-2.608^{* * *} \\
(0.866)\end{array}$ & $\begin{array}{c}-3.883^{* * *} \\
(0.874)\end{array}$ & $\begin{array}{c}-2.571^{* * *} \\
(0.894)\end{array}$ & $\begin{array}{c}-2.731^{* * *} \\
(0.899)\end{array}$ & $\begin{array}{r}-2.975^{* * *} \\
(0.959)\end{array}$ \\
\hline Right to work & $\begin{array}{c}-0.028^{* * *} \\
(0.009)\end{array}$ & $\begin{array}{c}-0.031^{* * *} \\
(0.008)\end{array}$ & $\begin{array}{c}-0.027^{* * *} \\
(0.009)\end{array}$ & $\begin{array}{c}-0.030^{* * *} \\
(0.010)\end{array}$ & $\begin{array}{c}-0.029^{* * *} \\
(0.009)\end{array}$ & $\begin{array}{c}-0.031^{* * *} \\
(0.011)\end{array}$ \\
\hline Small firms $(<250)$ & $\begin{array}{c}-0.443^{* * *} \\
(0.136)\end{array}$ & $\begin{array}{c}-0.504^{* * *} \\
(0.108)\end{array}$ & $\begin{array}{c}-0.233^{*} \\
(0.136)\end{array}$ & $\begin{array}{c}-0.463^{* * *} \\
(0.134)\end{array}$ & $\begin{array}{c}-0.445^{* * *} \\
(0.135)\end{array}$ & $\begin{array}{c}-0.452^{* * *} \\
(0.137)\end{array}$ \\
\hline Budget deficit & $\begin{array}{c}-0.132^{* *} \\
(0.063)\end{array}$ & $\begin{array}{c}-0.101^{*} \\
(0.054)\end{array}$ & & $\begin{array}{c}-0.135^{* *} \\
(0.066)\end{array}$ & $\begin{array}{c}-0.130^{*} \\
(0.067)\end{array}$ & $\begin{array}{c}-0.129^{*} \\
(0.066)\end{array}$ \\
\hline Intergov't transfers & $\begin{array}{c}0.193^{* *} \\
(0.073)\end{array}$ & $\begin{array}{l}0.134^{*} \\
(0.077)\end{array}$ & & $\begin{array}{l}0.187^{* *} \\
(0.073)\end{array}$ & $\begin{array}{c}0.192^{* *} \\
(0.076)\end{array}$ & $\begin{array}{c}0.201^{* *} \\
(0.081)\end{array}$ \\
\hline Construction & $\begin{array}{c}-2.421^{* * *} \\
(0.701)\end{array}$ & $\begin{array}{c}-2.685^{* * *} \\
(0.630)\end{array}$ & $\begin{array}{l}-0.859 \\
(0.863)\end{array}$ & $\begin{array}{c}-2.517^{* * *} \\
(0.669)\end{array}$ & $\begin{array}{c}-2.510^{* * *} \\
(0.771)\end{array}$ & $\begin{array}{c}-2.339^{* * *} \\
(0.717)\end{array}$ \\
\hline Public sector & & $\begin{array}{c}0.405^{* * *} \\
(0.134)\end{array}$ & $\begin{array}{c}0.123 \\
(0.148)\end{array}$ & & & \\
\hline Unemployment insurance & & & & $\begin{array}{l}-1.150 \\
(1.087)\end{array}$ & & \\
\hline Assistance/subsidies & & & & & $\begin{array}{c}0.358 \\
(1.141)\end{array}$ & \\
\hline Gov't debt & & & & & & $\begin{array}{l}-0.016 \\
(0.027)\end{array}$ \\
\hline Observations & 50 & 50 & 51 & 50 & 50 & 50 \\
\hline Adjusted $R^{2}$ & 0.719 & 0.744 & 0.628 & 0.716 & 0.713 & 0.714 \\
\hline
\end{tabular}

Table 3: Government Finance 


\begin{tabular}{lcccc}
\hline & $(1)$ & $(2)$ & $(3)$ & $(4)$ \\
\hline Manufacturing & $-0.379^{* * *}$ & $-0.417^{* * *}$ & $-0.379^{* * *}$ & $-0.317^{* * *}$ \\
& $(0.080)$ & $(0.100)$ & $(0.083)$ & $(0.085)$ \\
Mining & $0.475^{* * *}$ & $0.433^{* * *}$ & $0.454^{* * *}$ & $0.391^{* * *}$ \\
& $(0.099)$ & $(0.104)$ & $(0.087)$ & $(0.086)$ \\
Home vacancy rate & $-2.742^{* * *}$ & $-2.641^{* * *}$ & $-2.619^{* * *}$ & $-2.769^{* * *}$ \\
& $(0.866)$ & $(0.967)$ & $(0.876)$ & $(0.890)$ \\
Right to work & $-0.028^{* * *}$ & & $-0.029^{* * *}$ & $-0.029^{* * *}$ \\
& $(0.009)$ & & $(0.009)$ & $(0.009)$ \\
Small firms $(<250)$ & $-0.443^{* * *}$ & $-0.298^{*}$ & $-0.452^{* * *}$ & $-0.424^{* * *}$ \\
& $(0.136)$ & $(0.164)$ & $(0.139)$ & $(0.145)$ \\
Budget deficit & $-0.132^{* *}$ & $-0.173^{* *}$ & $-0.119^{*}$ & -0.090 \\
& $(0.063)$ & $(0.076)$ & $(0.064)$ & $(0.072)$ \\
Intergov't transfers & $0.193^{* *}$ & $0.206^{* * *}$ & $0.180^{* *}$ & $0.156^{* *}$ \\
& $(0.073)$ & $(0.073)$ & $(0.081)$ & $(0.077)$ \\
Construction & $-2.421^{* * *}$ & $-1.955^{* *}$ & $-1.943^{*}$ & \\
& $(0.701)$ & $(0.784)$ & $(0.979)$ & \\
Union membership & \multicolumn{5}{c}{0.001} & & \\
& & $(0.001)$ & & \\
Net estab. entry rate & \multicolumn{3}{c}{-0.800} & $-2.286^{* *}$ \\
& & & $(1.309)$ & $(1.014)$ \\
\hline Observations & 50 & 50 & 50 & 50 \\
Adjusted $R^{2}$ & 0.719 & 0.684 & 0.715 & 0.701 \\
All models include regional dummies. Dependent variable: IRF at 2 year horizon \\
${ }^{*} p<0.10,{ }^{* *} p<0.05,{ }^{* * *} p<0.01$ & & &
\end{tabular}

Table 4: Labour Market 


\begin{tabular}{|c|c|c|c|c|c|c|}
\hline & (1) & (2) & (3) & (4) & (5) & (6) \\
\hline Manufacturing & $\begin{array}{c}-0.379^{* * *} \\
(0.080)\end{array}$ & $\begin{array}{c}-0.430^{* * *} \\
(0.080)\end{array}$ & $\begin{array}{c}-0.457^{* * *} \\
(0.107)\end{array}$ & $\begin{array}{c}-0.453^{* * *} \\
(0.080)\end{array}$ & $\begin{array}{c}-0.396^{* * *} \\
(0.075)\end{array}$ & $\begin{array}{r}-0.416^{* * *} \\
(0.078)\end{array}$ \\
\hline Mining & $\begin{array}{c}0.475^{* * *} \\
(0.099)\end{array}$ & $\begin{array}{c}0.365^{* * *} \\
(0.104)\end{array}$ & $\begin{array}{c}0.511^{* * *} \\
(0.104)\end{array}$ & $\begin{array}{c}0.507^{* * *} \\
(0.099)\end{array}$ & $\begin{array}{c}0.523^{* * *} \\
(0.098)\end{array}$ & $\begin{array}{c}0.552^{* * *} \\
(0.103)\end{array}$ \\
\hline Home vacancy rate & $\begin{array}{c}-2.742^{* * *} \\
(0.866)\end{array}$ & & & & & \\
\hline Right to work & $\begin{array}{c}-0.028^{* * *} \\
(0.009)\end{array}$ & $\begin{array}{c}-0.030^{* * *} \\
(0.008)\end{array}$ & $\begin{array}{c}-0.034^{* * *} \\
(0.011)\end{array}$ & $\begin{array}{c}-0.027^{* * *} \\
(0.010)\end{array}$ & $\begin{array}{c}-0.019^{* *} \\
(0.009)\end{array}$ & $\begin{array}{c}-0.021^{*} \\
(0.011)\end{array}$ \\
\hline Small firms $(<250)$ & $\begin{array}{c}-0.443^{* * *} \\
(0.136)\end{array}$ & $\begin{array}{c}-0.318^{* *} \\
(0.132)\end{array}$ & $\begin{array}{c}-0.362^{* *} \\
(0.162)\end{array}$ & $\begin{array}{c}-0.356^{* * *} \\
(0.123)\end{array}$ & $\begin{array}{c}-0.458^{* * *} \\
(0.146)\end{array}$ & $\begin{array}{r}-0.421^{* * *} \\
(0.151)\end{array}$ \\
\hline Budget deficit & $\begin{array}{c}-0.132^{* *} \\
(0.063)\end{array}$ & $\begin{array}{c}-0.125^{* *} \\
(0.055)\end{array}$ & $\begin{array}{l}-0.127^{*} \\
(0.066)\end{array}$ & $\begin{array}{c}-0.156^{* *} \\
(0.063)\end{array}$ & $\begin{array}{c}-0.167^{* *} \\
(0.067)\end{array}$ & $\begin{array}{r}-0.176^{* *} \\
(0.071)\end{array}$ \\
\hline Intergov't transfers & $\begin{array}{l}0.193^{* *} \\
(0.073)\end{array}$ & $\begin{array}{l}0.130^{*} \\
(0.065)\end{array}$ & $\begin{array}{c}0.226^{* * *} \\
(0.077)\end{array}$ & $\begin{array}{l}0.201^{* *} \\
(0.080)\end{array}$ & $\begin{array}{c}0.237^{* * *} \\
(0.068)\end{array}$ & $\begin{array}{c}0.265^{* * *} \\
(0.074)\end{array}$ \\
\hline Construction & $\begin{array}{c}-2.421^{* * *} \\
(0.701)\end{array}$ & $\begin{array}{c}-1.842^{* *} \\
(0.870)\end{array}$ & $\begin{array}{c}-3.137^{* * *} \\
(0.926)\end{array}$ & $\begin{array}{c}-2.404^{* * *} \\
(0.722)\end{array}$ & $\begin{array}{c}-2.653^{* * *} \\
(0.672)\end{array}$ & $\begin{array}{c}-2.861^{* * *} \\
(0.659)\end{array}$ \\
\hline Home vacancy rate $(\mathrm{sd})$ & & $\begin{array}{c}-0.121^{* * *} \\
(0.030)\end{array}$ & & & & \\
\hline Home ownership rate & & & $\begin{array}{c}0.044 \\
(0.135)\end{array}$ & & & \\
\hline Home ownership rate (sd) & & & & $\begin{array}{c}-0.021^{* *} \\
(0.010)\end{array}$ & & \\
\hline Rental vacancy rate & & & & & $\begin{array}{c}-1.123^{* * *} \\
(0.351)\end{array}$ & \\
\hline Rental vacancy rate $(\mathrm{sd})$ & & & & & & $\begin{array}{c}-0.012^{* *} \\
(0.005)\end{array}$ \\
\hline Observations & 50 & 50 & 50 & 50 & 50 & 50 \\
\hline Adjusted $R^{2}$ & 0.719 & 0.749 & 0.674 & 0.704 & 0.727 & 0.705 \\
\hline
\end{tabular}

Table 5: Housing Market 


\begin{tabular}{lccc}
\hline & $(1)$ & $(2)$ & $(3)$ \\
& IRF 1qt & IRF 3yr & IRF 4yr \\
\hline Manufacturing & $-0.035^{* * *}$ & $-0.574^{* * *}$ & $-0.667^{* * *}$ \\
& $(0.010)$ & $(0.117)$ & $(0.136)$ \\
Mining & $0.038^{* * *}$ & $0.703^{* * *}$ & $0.818^{* * *}$ \\
& $(0.011)$ & $(0.154)$ & $(0.191)$ \\
Home vacancy rate & -0.064 & $-4.373^{* * *}$ & $-5.568^{* * *}$ \\
& $(0.105)$ & $(1.333)$ & $(1.626)$ \\
Right to work & $-0.003^{* *}$ & $-0.036^{* *}$ & $-0.038^{* *}$ \\
& $(0.001)$ & $(0.013)$ & $(0.016)$ \\
Small firms $(<250)$ & $-0.035^{* * *}$ & $-0.641^{* * *}$ & $-0.727^{* * *}$ \\
& $(0.013)$ & $(0.208)$ & $(0.261)$ \\
Budget deficit & $-0.016^{* *}$ & $-0.191^{* *}$ & $-0.209^{*}$ \\
& $(0.008)$ & $(0.093)$ & $(0.111)$ \\
Intergov't transfers & 0.011 & $0.301^{* * *}$ & $0.371^{* * *}$ \\
& $(0.007)$ & $(0.108)$ & $(0.126)$ \\
Construction & $-0.149^{*}$ & $-3.835^{* * *}$ & $-4.826^{* * *}$ \\
& $(0.077)$ & $(1.138)$ & $(1.458)$ \\
\hline Observations & 50 & 50 & 50 \\
Adjusted $R^{2}$ & 0.545 & 0.715 & 0.704 \\
All models include regional dummies & & \\
${ }^{*} p<0.10,{ }^{* *} p<0.05,{ }^{* * *} p<0.01$ & &
\end{tabular}

Table 6: Using IRFs at different horizons 


\begin{tabular}{lcc}
\hline & $(1)$ & $(2)$ \\
& IRF 2yr & IRF 2 yr sensitivity \\
\hline Manufacturing & $-0.379^{* * *}$ & -1.481 \\
& $(0.080)$ & $(0.913)$ \\
Mining & $0.475^{* * *}$ & $4.993^{* * *}$ \\
& $(0.099)$ & $(1.245)$ \\
Home vacancy rate & $-2.742^{* * *}$ & -14.171 \\
& $(0.866)$ & $(9.135)$ \\
Right to work & $-0.028^{* * *}$ & $-0.251^{* *}$ \\
& $(0.009)$ & $(0.105)$ \\
Small firms $(<250)$ & $-0.443^{* * *}$ & $-4.091^{* *}$ \\
& $(0.136)$ & $(1.729)$ \\
Budget deficit & $-0.132^{* *}$ & $-1.468^{*}$ \\
& $(0.063)$ & $(0.765)$ \\
Intergov't transfers & $0.193^{* *}$ & 0.797 \\
& $(0.073)$ & $(0.618)$ \\
Construction & $-2.421^{* * *}$ & -3.073 \\
& $(0.701)$ & $(7.004)$ \\
\hline Observations & 50 & 50 \\
Adjusted $R^{2}$ & 0.719 & 0.660 \\
All models include regional dummies & \\
${ }^{*} p<0.10,{ }^{* *} p<0.05,{ }^{* * *} p<0.01$ & \\
& &
\end{tabular}

Table 7: Comparison using IRFs from the simple FAVAR 
Table 8: Data for the factor model.

\begin{tabular}{|l|l} 
Variable \\
1 \\
2 \\
3 \\
4 \\
\\
5 \\
6 \\
\\
7 \\
\\
8 \\
9 \\
10 \\
\\
11 \\
12 \\
13 \\
14 \\
15 \\
\\
16 \\
17 \\
18 \\
19 \\
20 \\
21 \\
22 \\
23 \\
24 \\
25 \\
28 \\
29 \\
\\
29 \\
\end{tabular}

\begin{tabular}{|l|l} 
Description & Source \\
Industrial Production & FRED \\
Industrial Production: Business Equipment & FRED \\
Industrial Production: Consumer Goods & FRED \\
Industrial Production: Durable Consumer & FRED \\
Goods & \\
Industrial Production: Durable Materials & FRED \\
Industrial Production: Final Products & FRED \\
(Market Group) & \\
Industrial Production: Final Products and & FRED \\
Nonindustrial Supplies & \\
Industrial Production: Manufacturing & FRED \\
Industrial Production: Materials & FRED \\
Industrial Production: Nondurable Con- & FRED \\
sumer Goods & \\
Dow Jones Industrial Index & GFD \\
GDP Deflator & FRED \\
ISM Manufacturing: New Orders Index & FRED \\
ISM Manufacturing: Inventories Index & FRED \\
ISM Manufacturing: Supplier Deliveries In- & FRED \\
dex & \\
ISM Manufacturing: PMI Composite Index & FRED \\
ISM Manufacturing: Employment Index & FRED \\
ISM Manufacturing: Production Index & FRED \\
ISM Manufacturing: Prices Index & FRED \\
Employment & FRED \\
All Employees: Construction & FRED \\
All Employees: Financial Activities \\
All Employees: Goods-Producing Indus- \\
tries FRED \\
All Employees: Government \\
All Employees: Trade, Transportation and \\
Utilities FRED \\
All Employees: Retail Trade \\
All Employees: Wholesale Trade \\
All Employees: Durable goods \\
All Employees: Manufacturing \\
All Employees: Nondurable goods \\
All Employees: Service-Providing Indus- \\
tries FRED \\
\end{tabular}

\begin{tabular}{|l} 
Transformation \\
D \\
D \\
D \\
D \\
D \\
D \\
D \\
D \\
D \\
D \\
D \\
N \\
N \\
N \\
N \\
N \\
N \\
N \\
N \\
D \\
D \\
D \\
D \\
D \\
D \\
D \\
D \\
D \\
D \\
D \\
D \\
\end{tabular}


Table 8: Data for the factor model.

All Employees: Total Nonfarm Payrolls

FRED

Real personal income excluding current transfer receipts

Business Conditions Index

Imports

Exports

Real Government Spending

Real Tax revenues

Business Investment

Real Consumption Expenditure

Real GDP

Unemployment Rate

Number of Civilians Unemployed for 15

Weeks and Over

Number of Civilians Unemployed for 15 to 26 Weeks

Number of Civilians Unemployed for 27

Weeks and Over

Number of Civilians Unemployed for 5 to 14

Weeks

Number of Civilians Unemployed for Less

Than 5 Weeks

Average (Mean) Duration of Unemployment

Average Weekly Hours

Average Weekly Hours of Production and Nonsupervisory Employees: GoodsProducing

Average Hourly Earnings of Production and Nonsupervisory Employees: GoodsProducing

Average Hourly Earnings of Production and Nonsupervisory Employees: Construction Average Hourly Earnings of Production and Nonsupervisory Employees: Manufacturing Average Weekly Hours of Production and Nonsupervisory Employees: Manufacturing Civilian Labour Force

Civilian Participation Rate

GFD

Fred

Fred

Fred

Fred

Fred

Fred

Fred

Fred

Fred

Fred

Fred

Fred

Fred

Fred

Fred

Fred

Fred

Fred

Fred

Fred

Fred

Fred

Unit Labour Cost

Fred 
Table 8: Data for the factor model.

59

60

61

62

63

64

65

66

67

68
Nonfarm Business Sector: Real Compensation Per Hour

M2 Money

Total Consumer Credit Owned and Securitized, Outstanding

Commercial and Industrial Loans, All Commercial Banks

Real Estate Loans, All Commercial Banks Producer Price Index for All Commodities Producer Price Index by Commodity Metals and metal products: Primary nonferrous metals

Producer Price Index by Commodity for

Crude Materials for Further Processing

Producer Price Index by Commodity for

Finished Consumer Goods

Producer Price Index by Commodity for

Finished Goods

Producer Price Index by Commodity Intermediate Materials: Supplies and Components

Consumer Price Index

Consumer Price Index for All Urban Consumers: Apparel

Consumer Price Index for All Urban Consumers: Medical Care

Consumer Price Index for All Urban Consumers: All items less shelter

Personal Consumption Expenditures:

Chain-type Price Index

3 Month Treasury Bill Rate

10 year Govt Bond Yield minus 3mth T-bill rate

6 mth T-Bill rate minus $3 \mathrm{mth}$ T-bill rate

1 year Govt Bond Yield minus 3mth T-bill rate

5 year Govt Bond Yield minus 3mth T-bill rate

Commodity Price Index

West Texas Intermediate Oil Price

Fred
Fred
Fred
Fred
Fred
Fred
Fred
Fred
Fred
Fred
Fred
GFD
GFD
Fred
Fred
Fred
Fred


Table 8: Data for the factor model.

BAA Corporate Spread

AAA Corporate Bond Spread

S\&P500 Total Return Index

NYSE Stock Market Capitalization

S\&P500 P/E Ratio

Pound dollar Exchange Rate

US and Canadian Dollar exchange rate

US dollar and German Mark exchange rate

Us Dollar and Japanese Yen Exchange Rate

Nasdaq Composite

NYSE Composite

GFD
GFD
GFD
GFD
GFD
GFD
GFD
GFD
GFD
GFD
GFD




\subsection{Data for Cross-section Analysis}

- Small establishment employment share: Employment at the 6-digit NAICS industry level, by state and establishment size, annual 1986 to 2013. Source: Census Bureau, County Business Patterns. Small establishments are defined as those with less than 250 employees. We aggregate to the state level, and average over time.

- Industry shares of GDP (oil, agriculture, finance, manufacturing): State-level GDP by industry, annual 1963 to 2013, average over time. Source: BEA. Industry classification is NAICS since 1997, SIC prior to that.

- Share of loans extended by small banks: Bank balance sheet data on all FDIC-insured financial institutions excluding bank holding companies, quarterly 2001Q1 to 2015Q3. Source: Call Reports from the FFIEC. Small banks are defined as at or below the 90th percentile of the national distribution of bank size by assets. The small bank loans share is the time-average of the fraction of total loans on small bank balance sheets in each state. The panel contains 449,777 observations, the cross-section contains on average 150 institutions per state.

- State government debt, deficit and intergovernmental transfers: State government sources of revenues and expenditures, annual 1992 to 2013, average over time. Source: Census Bureau. Intergovernment transfers are the sum of transfers to/from federal and local governments.

- Homeownership rate: Home ownership rates, quarterly 2005Q1-2015Q4, standard deviation over time. Source: Census Bureau.

- Union membership as a share of nonagricultural employment by state, average of 1984 and 2000. Source: Barry T. Hirsch (2001)

- Business creation: Net entry rate of establishments, 1977-2014 average. Source: Census Bureau.

- Right to work: Dummy for whether a state has right to work legislation as of 2016. Source: http://www.nrtw.org/rightto-work-states/.

\section{Recursive means of retained draws}



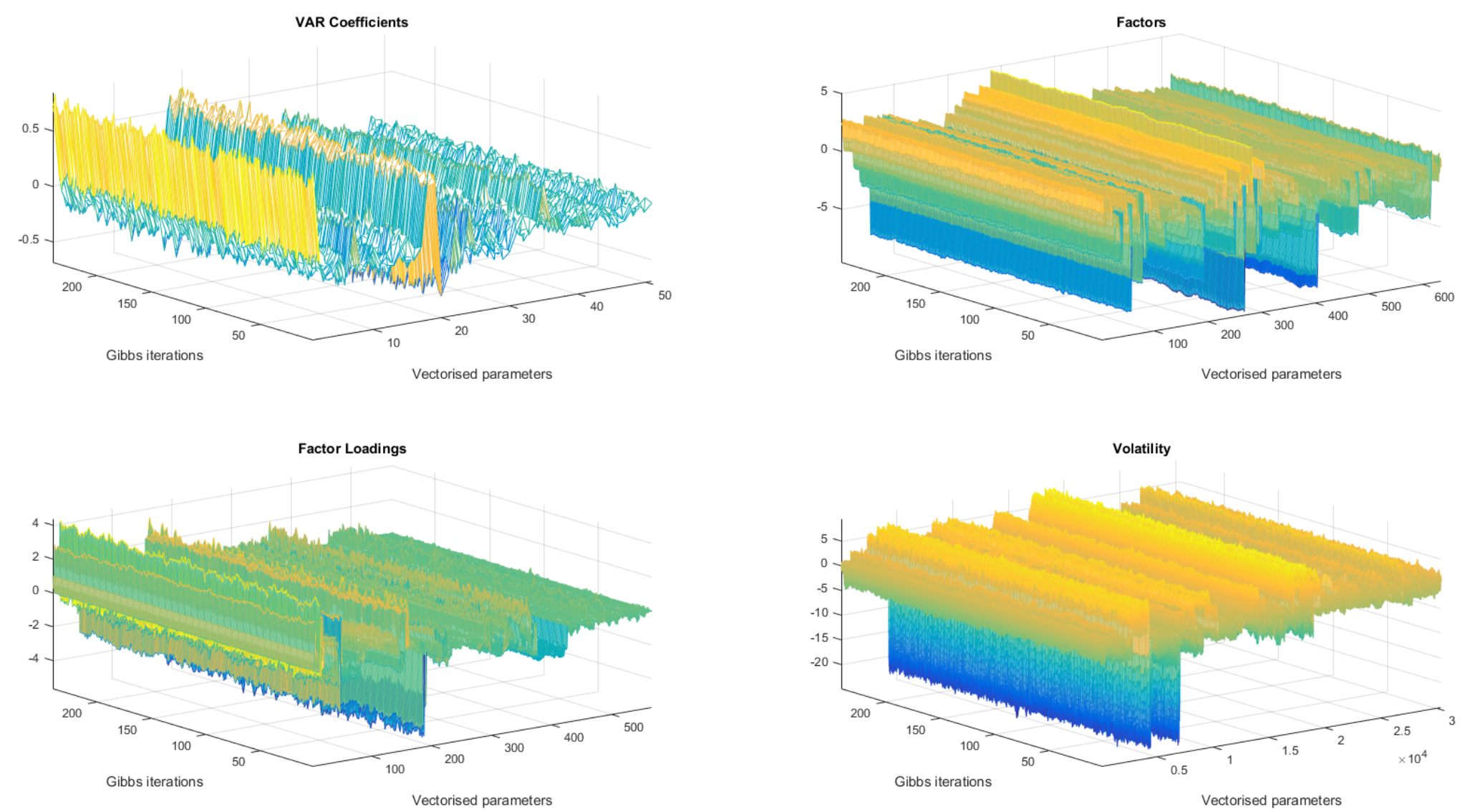

Figure 1: Recursive means calculated every 20 draws 


\section{References}

Banbura, Marta, Domenico Giannone and Lucrezia Reichlin, 2010, Large Bayesian vector auto regressions, Journal of Applied Econometrics 25(1), 71-92.

Barry T. Hirsch, David A. Macpherson, Wayne G. Vroman, 2001, Estimates of union density by State, Monthly Labor Review 124(7), 51-55.

Carlin, Bradley P., Nicholas G. Polson and David S. Stoffer, 1992, A Monte Carlo Approach to Nonnormal and Nonlinear State-Space Modeling, Journal of the American Statistical Association 87(418), 493-500.

Carter, C and P Kohn, 2004, On Gibbs sampling for state space models, Biometrika 81, 541-53.

Jacquier, E, N Polson and P Rossi, 1994, Bayesian analysis of stochastic volatility models, Journal of Business and Economic Statistics 12, 371-418.

Jurado, Kyle, Sydney C. Ludvigson and Serena Ng, 2015, Measuring Uncertainty, American Economic Review 105(3), 1177-1216. 